\title{
Vulnerability to Climate Change: A Sub-regional Analysis of Socio-economic and Agriculture Sectors in Karnataka, India
}

Journal of Development Policy and Practice 2(I) 24-55

(c) 2017 SAGE Publications India (Pvt) Ltd and Aequitas Consulting Pvt. Ltd

SAGE Publications sagepub.in/home.nav DOI: I0.II77/2455|333|6676402 http://jdp.sagepub.com

@SAGE

\author{
K. V. Raju' \\ R. S. Deshpande ${ }^{2}$ \\ Satyasiba Bedamatta ${ }^{3}$
}

\begin{abstract}
Vulnerability assessments can play a vital role in the designing of appropriate adaptation and mitigation policies targeted towards climate change and its impacts on ecosystems, and for those who depend upon the sensitive resources for their livelihoods and well-being. Vulnerability is often reflected in the economic system as well as the socio-economic features of the population living in that system. This article attempts to build a picture of the socio-economic context of vulnerability by focusing on indicators that measure both the state of socio-economic development of the people as well as their capacity to progress further. The result of agricultural vulnerability index suggests indicators such as cropping intensity, gross irrigated area and commercial crop area are the major drivers in determining the vulnerability of the districts of Karnataka. The socio-economic and livelihood index depicts indicators like per capita income, population density and percentage of literacy rate are the major drivers and contribute to the overall livelihood vulnerability of districts.
\end{abstract}

\section{Keywords}

Climate change, vulnerability index, principal component analysis, agricultural vulnerability, socio-economic vulnerability, Karnataka, India

\footnotetext{
'Theme Leader, Policy and Impact Group, Regional Program-Asia, International Crop Research Institute for the Semi-Arid Tropics, Patancheru, Telangana, India.

${ }^{2}$ Rajiv Gandhi Fellow, ICSSR, India.

${ }^{3}$ CEENR, Institute for Social and Economic Change, Bangalore, India.
} 


\section{Introduction}

Climate change is an ongoing phenomenon and over centuries, climate has changed substantially around the world. ${ }^{1}$ However, the pace and pattern of changes in climatic variables in recent decades have become a matter of concern. It is quite difficult to understand the impact of change in climatic variables at the micro level even, say, at provincial or district levels. It is only feasible to speak about such changes at the global scale as vulnerability to natural hazards varies widely across communities, sectors and regions. The socio-economic vulnerability is determined by the internal structure of any social system that decides sensitivity of societies and communities to the incidence of hazards. The internal structure also helps to cope with damages from external shocks. It poses the important research question as to why there are different levels of vulnerability within a particular society, even in the context of similar hazards. The possible answer may be that individuals and groups differ in terms of equality, entitlement capacity, institutions and political and cultural aspects that are responsible factors for the differential vulnerability. For example, marginalised communities are forced to live in susceptible regions that expose them to floods/droughts and different diseases as compared to other people. The measurement in absolute terms is difficult, but ordinal measurement is possible and could be attempted. Such attempts have been available, but the fragility of methodology directly relates to the use of the vulnerability ranking. That will facilitate a move towards the policy preparation.

\section{Vulnerability}

A growing body of literature over the past two decades has identified climate change as the prime issue to global environmental degradation and has analysed the associated vulnerability and biodiversity loss (IPCC, 2007). According to Fussel (2007), climate related vulnerability assessments are based on the characteristics of the vulnerable system spanning over physical, economic and social factors. The Intergovernmental Panel on Climate Change (IPCC), in its second assessment report (IPCC, 1996), defines vulnerability as 'the extent to which climate change may damage or harm a system'. It adds that vulnerability 'depends not only on a system's sensitivity, but also on its ability to adapt to new climatic conditions'; and vulnerability depends on the level of economic development and institutions. Watson, Zinyoera and Moss (1996) argued that socio-economic systems 'typically are more vulnerable in developing countries where economic and institutional circumstances are less favourable'. In addition, social scientists tend to view vulnerability as representing the set of socioeconomic factors that determine people's ability to cope with stress or change (Allen, 2003), while climate scientists often view vulnerability in terms of the likelihood of occurrence and impacts of weather- and climate-related events (Nicholls, Hoozemans, \& Marchand, 1999). 
IPCC defines vulnerability in terms of systems as 'the degree to which a system is susceptible to, or unable to cope with, adverse effects of climate change, including climate variability and extremes (IPCC, 2007). Vulnerability is a function of the character, magnitude and rate of climate variation to which a system is exposed, its sensitivity and its adaptive capacity (IPCC, 2007).

It is well understood that poor people in the poorest countries are the most vulnerable to the impacts of anthropogenic climate change (Stern et al., 2006). The poor are adversely impacted by climate change because they live in heavily impacted countries and locations within those countries, depend on natural resource-based livelihoods that are disproportionately affected by climate change, and have the weakest ability to adapt to the impacts. Small and marginal farmers are more vulnerable to both the current and future climate change impacts, given their high dependence on agriculture, strong reliance on the ecosystem and rapid population growth.

Vulnerability assessments even on ordinal scale can play a vital role in the design of appropriate adaptation and mitigation policies targeted towards climate change and its impacts on ecosystems and those who depend upon these resources for their livelihoods and well-being. Every community in the world has a tendency to be adversely affected by the changes in climate, regardless of the communities' contribution to that change. This tendency is simply known as vulnerability of that particular community to climate change impacts. Agricultural and social vulnerability explicitly focuses on those agricultural, demographic and socio-economic factors that increase or attenuate the impacts of hazard events on local populations.

People who live in arid or semi-arid regions, in low-lying coastal areas, in water-limited or flood-prone areas or on small islands are particularly vulnerable to climate change (Watson et al., 1996). It is clear that climate change will, in many parts of the world, adversely affect socio-economic sectors, including water resources, agriculture, forestry, fisheries and human settlements, ecological systems and human health with developing countries being the most vulnerable (IPCC, 2001). Developing countries have a lesser capacity to adapt and are more vulnerable to climate change damages, just as they are to other stresses. This condition is the most extreme among the poorest people (IPCC, 2001).

There is an increasing need to develop indicators of vulnerability and of adaptive capacity both to determine the robustness of response strategies over time and to understand better, the underlying processes (Adger, Brooks, Bentham, Agnew, \& Eriksen, 2004). Our approach towards assessing vulnerability goes through four groups of factors: causal factors; impact factors; structural factors; and socioeconomic factors. This approach is content-wise different than the earlier approaches in assessing vulnerability. At the district level, vulnerability assessments contribute to setting development priorities and monitoring progress. Sectoral assessments provide details and targets for strategic development plans. In Karnataka, farmers and agricultural labourers form 56 per cent of the total workforce (Government of Karnataka, 2005) and this is considered one of the driving forces in determining the socio-economic vulnerabilities of communities in Karnataka. In the present context, a district-wise socio-economic and agricultural vulnerability profile of Karnataka was developed. 


\section{Objectives, Method and Data}

The key objectives of this assessment are: (a) to assess vulnerability of agricultural sector across the districts of Karnataka; and (b) to estimate the socio-economic vulnerability of the districts of Karnataka.

Keeping in view the assessment through four groups of factors, as stated above, the data pertaining to various indicators were collected and compiled from different sources such as Government of India (2012a) and Government of Karnataka (2012), 2008-2009, 2009-2010 and 2010-2011. To understand the agricultural and socio-economic profile, the study analyses important indicators across the districts of Karnataka. This has been done by consultation with experts and based on previous studies (Table 1).

Vulnerability to climate change is a comprehensive process affected by a large number of indicators. However, it is not possible to consider all the available indicators, so only the most significant and representative indicators relevant to Karnataka state were selected in the development of vulnerability indices. We chose to group the indicators into two groups instead of the four-group classification used by Hiremath and Shiyani (2013). They used demographic, climate, agriculture and occupation. Out of these, climatic factors represent micro-climatic aberrations and are hence difficult to connect to the phenomenon of climate change at a broader level. Besides, climate-related variables are closely connected with the agricultural variables and hence this strong relationship could be used to reduce the unnecessary variables. Therefore, we stick to the most pertinent variables. Indicators considered in this study are:

- Agricultural Indicators: Net sown area (NSA) (3 years, average), cropping intensity (CI), area under commercial crops to the total cropped area (TCA), percentage irrigated area to TCA (3 years, average), number of tractors/1000 hectare area sown, total fallow land (3 years, average) and agricultural credit cooperative societies/lakh population.

- Socio-economic Indicators: Population density, percentage population of Scheduled Caste (SC) and Scheduled Tribe (ST), literacy rate (LR), percentage of marginal landholder $(<1$ hectare), percentage of non-workers, livestock units (LU) per lakh population, per capita income (3 years average), CI and percentage irrigated area to TCA (3 years average).

\section{Agricultural Vulnerability Index}

\section{Net Sown Area}

Agricultural activities play a dominant role in shaping livelihoods across the districts of Karnataka. NSA is an important indicator of the status of agricultural development in a district. The NSA refers to the particular area sown once during an agriculture year. In the present study, we have incorporated a 3-year average (to iron out year-to-year fluctuations) of the NSA. Hiremath and Shiyani (2013) used single year's data and that can bring in the bias due to the choice of year. 


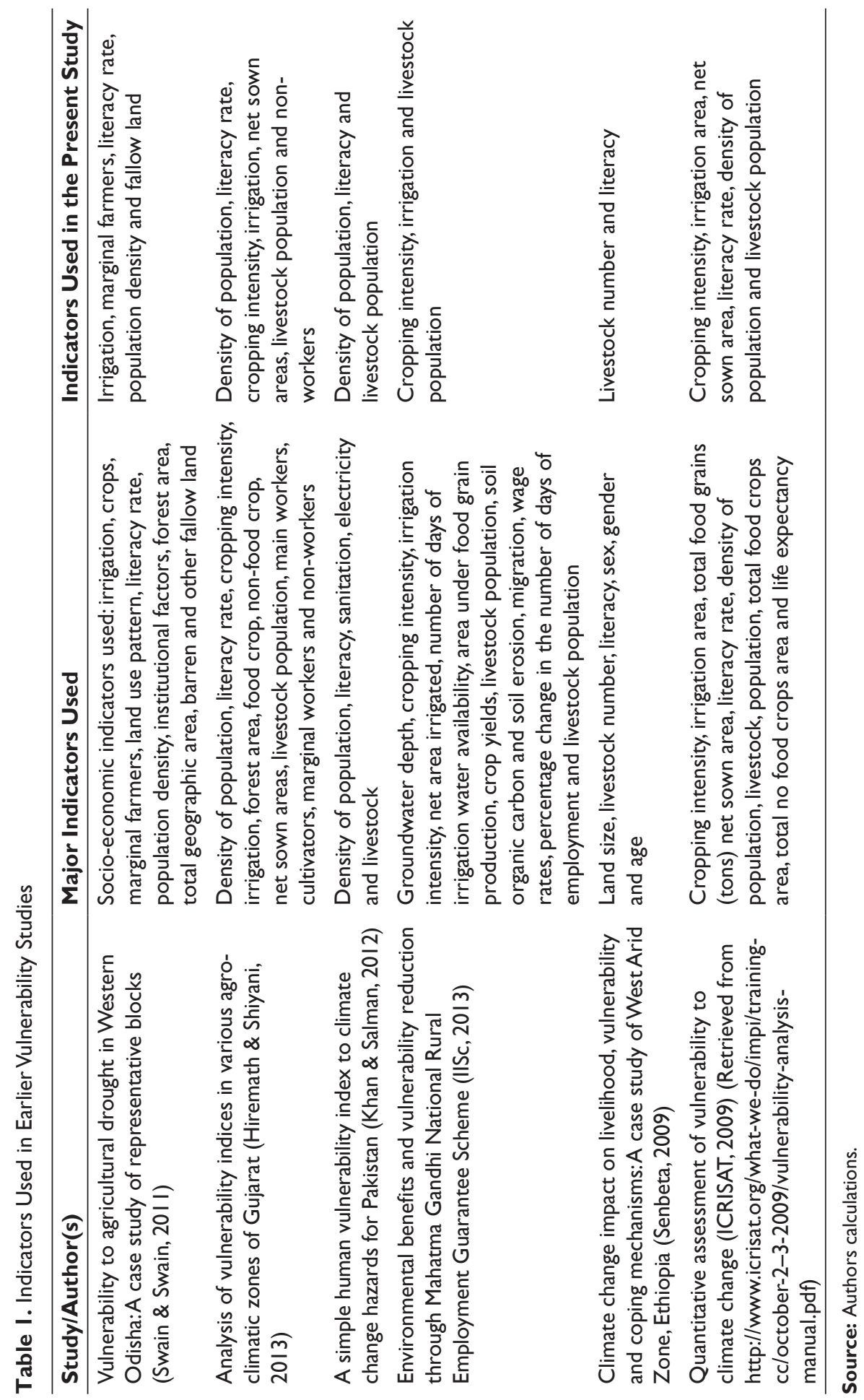


Districts from northern Karnataka have more NSA than the southern districts of Karnataka. The districts of Gulbarga and Gadag have the highest NSA of 87.04 per cent and 83.26 per cent, respectively. The districts of Uttara Kannada and Shimoga have the least NSA of 11.04 per cent and 26.21 per cent, respectively. Figure 1 presents district-wise percentage of NSA to the total geographical area. Districts with high NSA are above the median value and districts with low NSA are below the median value.

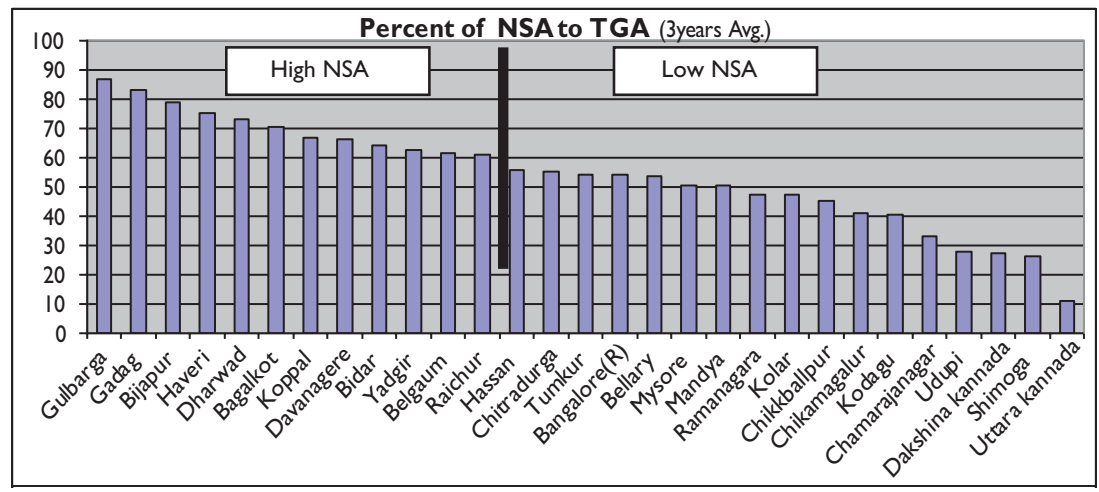

Figure I. Percentage Net Sown Area (NSA) of to the Total Geographical Area (3 Years Average) in Districts of Karnataka

Source: Based on Directorate of Economics and Statistics, Ministry of Agriculture, 2008-2009, 2009-2010.

\section{Commercial Crops}

Commercial crops are high value crops that are of crucial importance to the economy of a district. It was observed that in Karnataka cultivation of commercial crops has increased over the years. The economic value of commercial crops has encouraged farmers to grow them. The major commercial crops are sugarcane and cotton among others. The northern districts have been observed to perform better in terms of commercial crops as compared to the southern regions of Karnataka (Figure 2). This may be due to the fact that the quality of land in central and northern regions of Karnataka is more suitable for cotton and sugarcane cultivation. The districts of Belgaum and Haveri ranked first and second in the state, in terms of area under commercial crops to TCA, with 24.91 per cent and 24.90 per cent, respectively. Likewise, Mysore, Dharwad and Bagalkot districts also have a considerable percentage of area under commercial crops. The districts of Dakshina Kannada and Bangalore Rural have the least percentage of area under commercial crops. Figure 2 presents the percentage of area under commercial crops to TCA across the districts of Karnataka. 


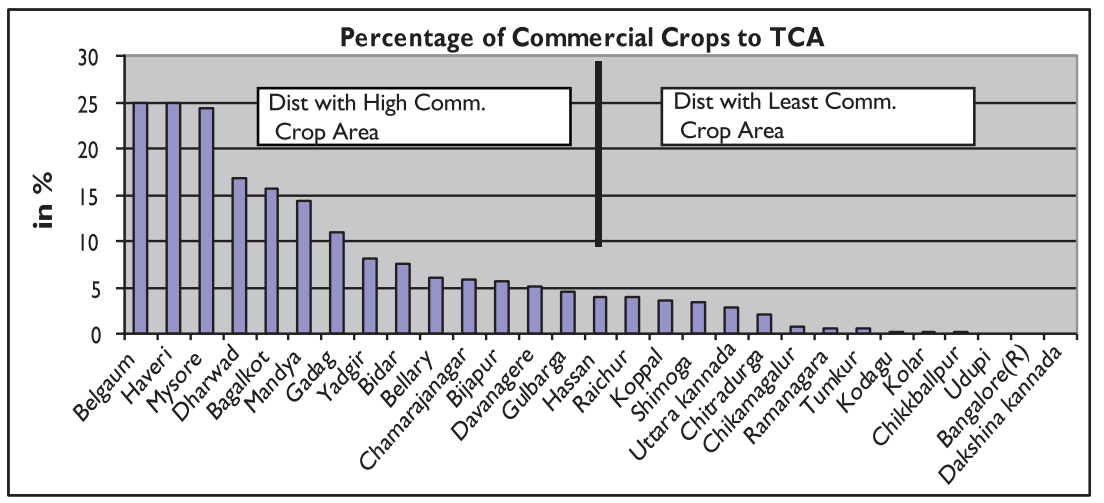

Figure 2. Percentage Area under Commercial Crops to the Total Cropped Area (3 Years Average) in Districts of Karnataka

Source: Based on Directorate of Economics and Statistics, Ministry of Agriculture (2008-2009, 2009-2010).

\section{Cropping Intensity}

CI refers to cultivation of more than one crop in the same field during the same agricultural year. Higher the CI essentially means more number of crops cultivated in a year. Normally, districts with more irrigation water availability have higher cropping intensities. In addition, mechanisation of farmlands have also had considerable effects on increasing cropping intensities. Dharwad district was observed to have the highest CI of 164.74 per cent followed by Mysore with 162.33 per cent. Bellary, Raichur and Koppal were also found to have good cropping intensities. The government has encouraged farmers to adopt water conservation methods and has focused on developing irrigation provisioning facilities in these regions, thereby leading to increased cropping intensities in these districts.

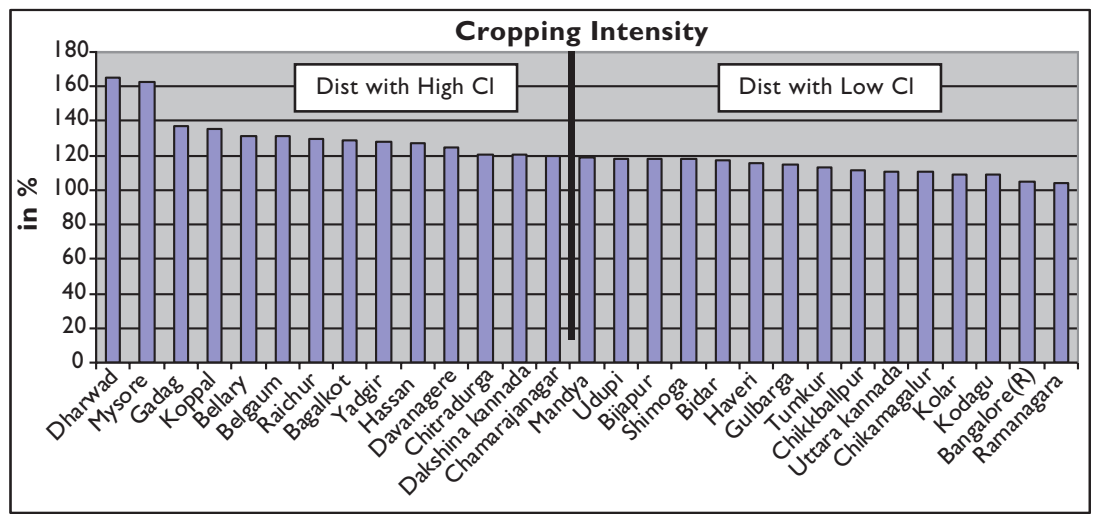

Figure 3. Cropping Intensity $(\mathrm{Cl})$ Across the Districts of Karnataka

Source: Based on Directorate of Economics and Statistics, Ministry of Agriculture, 2010-20I I. 


\section{Gross Irrigated Area}

Irrigation water availability is essential for climate resilient agricultural production. In Karnataka, a large portion of area is under rainfed-agriculture. Karnataka is one of the states with less irrigated area in the country; that is, 32 per cent of gross irrigated area to TCA (Government of India, 2012b). Among the different districts, Shimoga has the highest area of about 62 per cent of its TCA under irrigation and the least in the state is in Kodagu district (2.34 per cent). In the northern region of Karnataka, Belgaum district has 48.9 per cent of TCA under irrigation and in southern Karnataka, the district of Mandya has 57.52 per cent area under irrigation, which is the second highest in the state. The districts of northern Karnataka, namely, Bagalkot, Bellary, Yadgir, Raichur, Koppal and Bijapur have significant areas under irrigation after Belgaum. Bidar district has the least area under irrigation in the northern region (12.77 per cent). The existing major reservoirs in the northern regions have the potential to bring additional area under irrigation. Figure 4 presents the percentage of irrigated area to TCA across the districts of Karnataka.

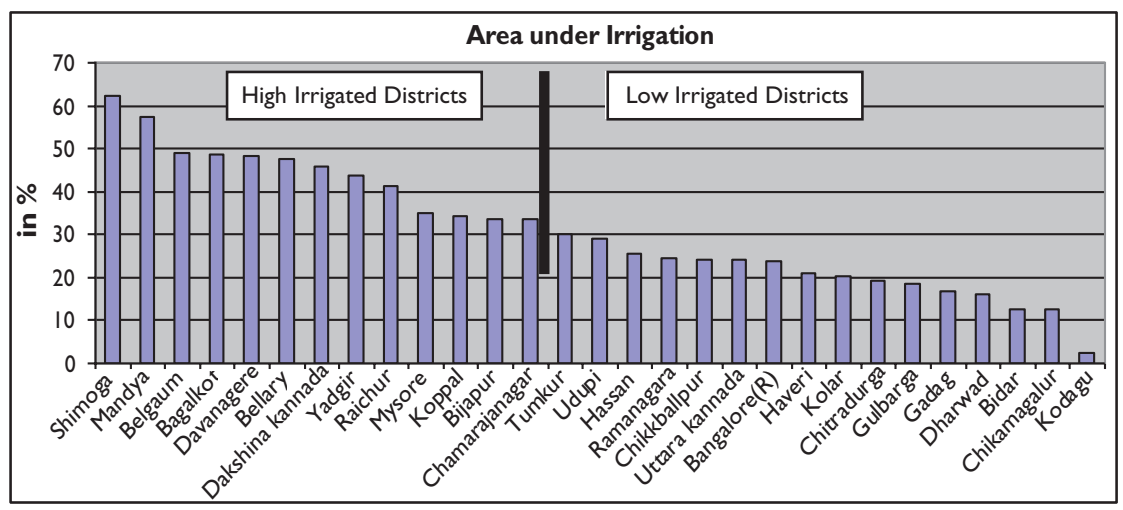

Figure 4. Gross Irrigated Area As a Percentage of Total Cropped Area (3 Years Average) in Districts of Karnataka

Source: Based on Directorate of Economics and Statistics, Ministry of Agriculture, 2008-2009, 2009-2010).

\section{Fallow Land}

Agricultural development is dependent on proper utilisation of available land resources. Fallow land refers to the cultivable area that has not been cultivated for a period of time. The districts where large areas have been left fallow can be considered as districts where there is underutilisation of land resources. Raichur has the highest percentage of fallow land to its total geographical area. It has about 26.46 per cent of its geographical area under fallow land, followed by Yadgir with 17.04 per cent of area under fallow land. The districts of Uttara Kannada and Kodagu have only 1.89 per cent and 2.08 per cent of area under fallow land, respectively, the least in the state. In northern Karnataka, the districts 
of Haveri and Gadag also have less area under fallow land, about 3.37 per cent and 4.16 per cent, respectively. Figure 5 depicts the average percentage of area under fallow land over 3 years across the districts of Karnataka.

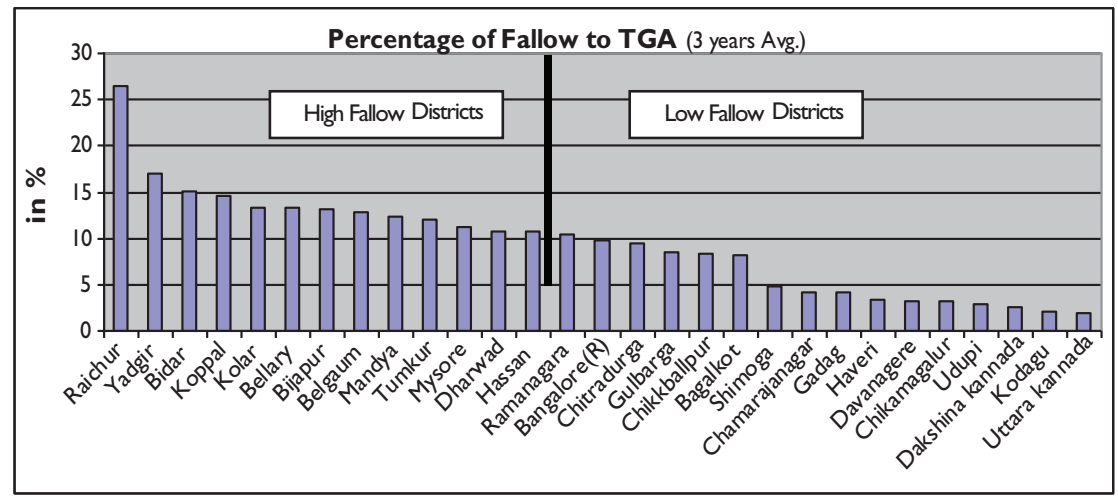

Figure 5. Average Percentage of Fallow Land to Total Geographical Area (3 Years Average) Across Districts of Karnataka

Source: Based on Directorate of Economics and Statistics, Ministry of Agriculture, 2008-2009, 2009-2010.

\section{Agricultural Credit Cooperative Societies}

The role of institutions providing financial support to farmers is extremely important for sustainable agricultural production, as it ensures supply of agricultural credit and funds during the different stages of crop production and has the potential to deliver goods and services. Agricultural finance is a critical factor that impacts the development of agricultural activities in the state. The agricultural cooperative societies (ACS) are considered, as the grass root financial institutions for the farming communities and provide credit to cultivars in time. At the state level, Belgaum district has the highest number of ACS/lakh population, where it has 16 cooperatives. Likewise in southern Karnataka, Mandya district also has many cooperative societies per lakh population-about 13 agricultural cooperatives. The districts of Udupi and Dakshina Kannada have only 4 and 5 cooperatives per lakh population, respectively, which is the least in the state. Figure 6 represents the number of agricultural credit cooperative societies per lakh population across the districts of Karnataka.

\section{Socio-economic Vulnerability Index}

\section{Population Density}

Higher the population density, higher will be the dependency on finite resources. Further, higher density of population could also potentially trigger environmental and health problems (Hiremath and Shiyani, 2013). The density of population in 
Mysore district is the highest among all the districts in the state (476 persons/sq. $\mathrm{km})$. The lowest population density in the state of about 135 persons/sq. $\mathrm{km}$ is in Kodagu district. In the northern districts, the main reason for migration is severe drought for consecutive years. Figure 7 gives the details of population density across the districts of Karnataka.

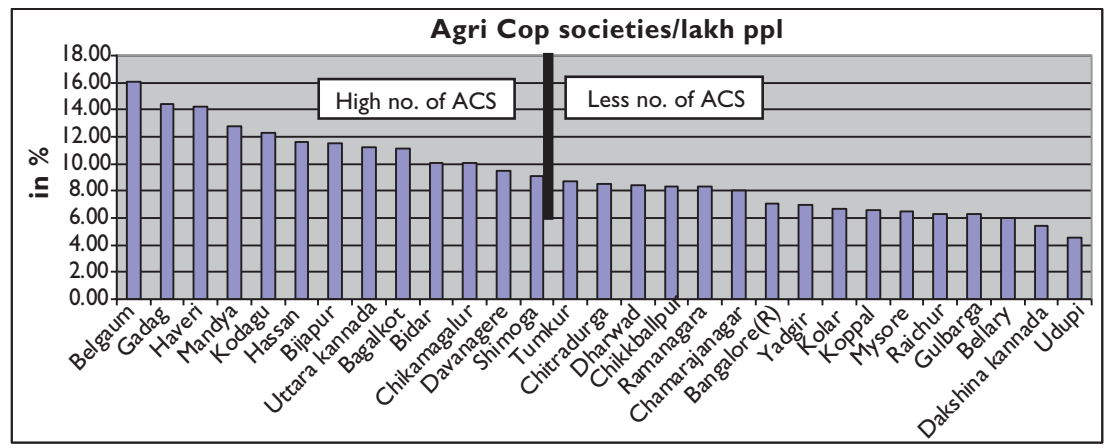

Figure 6. Agricultural Cooperative Societies (ACS) (No. Lakh Population) in Various Districts of Karnataka

Source: Based on the Department of Co-operation cited in DES, 2010-20II.

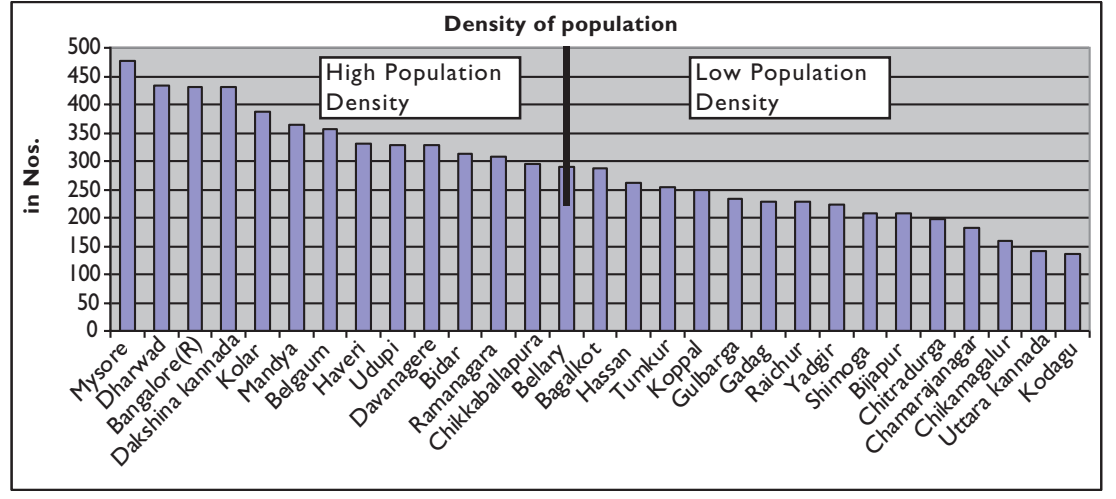

Figure 7. Population Density in Different Districts of Karnataka

Source: Based on Census of India, 20I I.

Note: Bangalore Urban is not included here as it is an outlier.

\section{SC and ST Population}

SC and ST are considered the deprived sections of society (Karade, 2008). Districts in southern Karnataka such as Kolar, Chikkaballapura, Chamarajanagar and Chitradurga have the highest percentage of this category. Kolar has the highest of 30.32 per cent SC population in the state, followed by Chamarajanagar with 25.42 per cent. The population of SC is more in southern districts of Karnataka compared to the northern districts. In northern region of Karnataka, Raichur has 19.03 per cent 
of ST population, the highest in the state, followed by Bellary district. The ST population in the southern Karnataka district of Chitradurga also constitutes a large percentage (18.23 per cent), while other districts like Chikkaballapura, Davanagere and Chamarajanagar and Kodagu too have high percentages of ST population. Total of SC and ST is the highest in Chitradurga district, while the percentage is the lowest in Uttara Kannada (Figure 8).

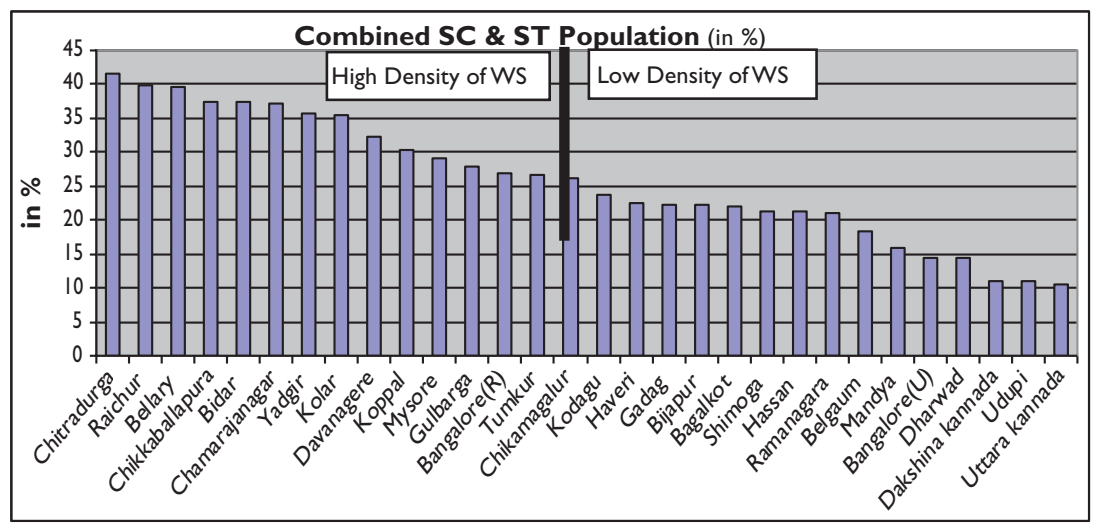

Figure 8. Percentage of Total Scheduled Caste (SC) and Scheduled Tribe (ST) Population in the Districts of Karnataka

Source: Based on Census of India (20II).

\section{Literacy Rate}

Higher LRs could enable communities to diversify their employment and income sources, enhance standards of living and increase their resilience towards any kind of shock or stress. This is due to the fact that higher the LR, higher is the adaptive capacity, the appropriation of opportunities and the awareness to face any pressure. The LR in Karnataka state has considerably increased in recent years. The coastal district of Dakshina Kannada has the highest literacy of 88.57 per cent in the state. Other coastal districts such as Udupi and Uttara Kannada have recorded 86.24 per cent and 84.06 per cent, respectively. The southern district of Bangalore Urban marks second with 87.67 per cent. Bidar district has 70.51 per cent and Yadgir has 51.83 per cent LR in the Hyderabad-Karnataka region. Yadgir, Raichur and Bellary districts have lower LRs as compared to the rest of Karnataka. Poverty and lack of socio-economic development are the main reasons for poor LR. Figure 9 shows the LRs across the districts of Karnataka.

\section{Marginal Landholders}

The size of landholdings is an important indicator of overall agricultural and socio-economic development. In Karnataka, a majority of the farmers belong to the marginal landholdings category; Udupi district has the highest percentage 
(79.8 per cent) of marginal landholders (Figure 10). Mandya, Ramanagara, Dakshina Kannada and Bangalore Urban districts also have significant percentages of marginal landholders. The size of landholding is greater in the northern districts as compared to the southern districts of Karnataka.

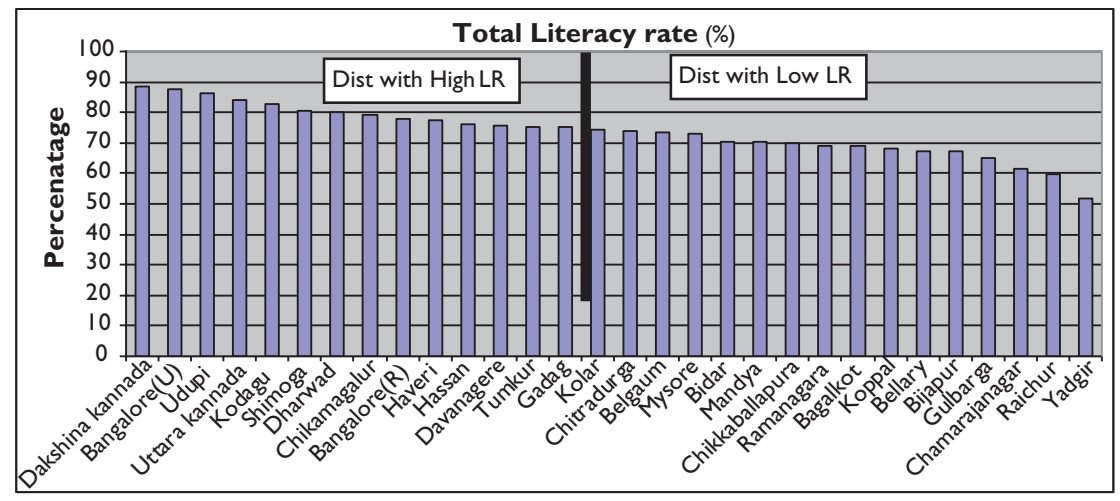

Figure 9. Literacy Rate (LR) Across the Districts of Karnataka

Source: Based on Census of India (201 I).

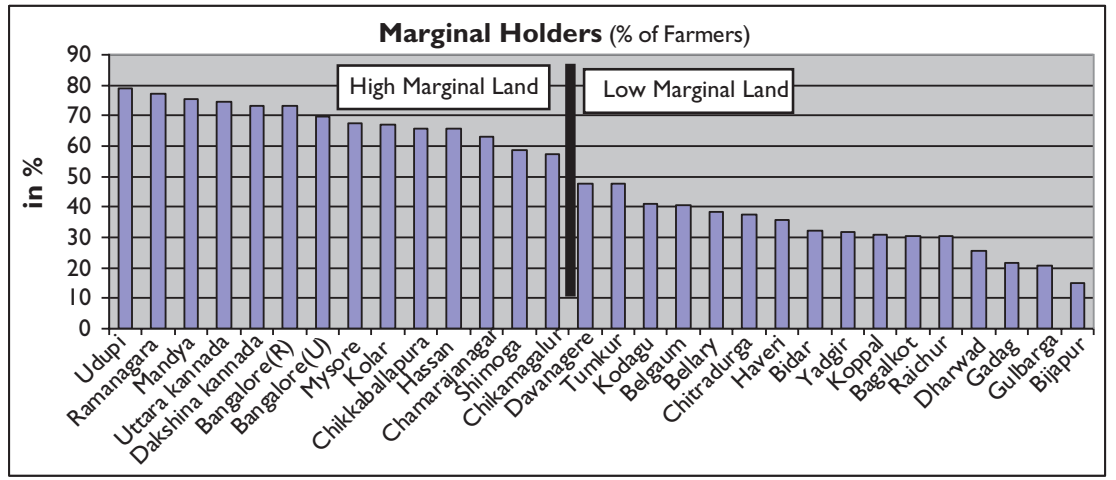

Figure 10. Percentage of Marginal Landholders in Different Districts of Karnataka

Source: Based on the Directorate of Economics and Statistics, Agriculture Census 2010-20I I.

\section{Non-workers}

Higher the percentage of non-workers, higher will be the dependency rate. Higher dependency rate suggests the district is more vulnerable. This is due to the fact that the number of persons having income source is less. The district of Bidar has 58.75 per cent of non-workers and is the highest in the state (Figure 11). Other districts like Gulbarga, Uttara Kannada, Bijapur, Bagalkot, Mysore, Shimoga and Udupi also have a high percentage of non-workers. Figure 11 shows the percentage of non-workers across the districts of Karnataka. 


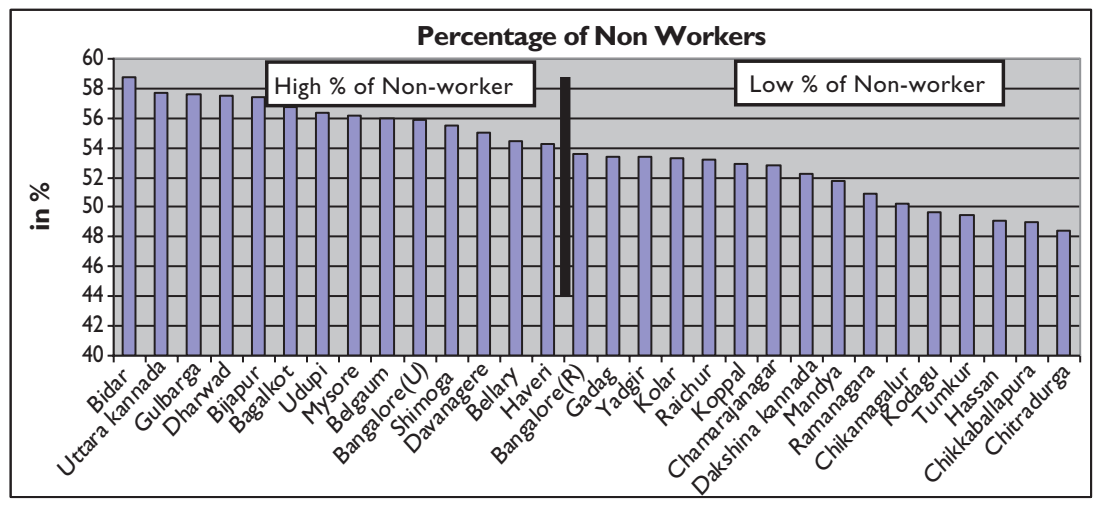

Figure I I. Percentage of Non-workers Across the Districts of Karnataka

Source: Based on the Census of India (2011).

\section{Livestock Units}

Livestock practices are considered an important source of livelihood for rural communities. Agriculture and livestock are an integral part of the farmer community. Livestock provides enormous opportunities to farmers to support their sustainable livelihood. The LU per lakh population is the highest $(58,431)$ in Yadgir district and the lowest in Bangalore Urban district (1693) (Figure 12). Districts such as Belgaum, Tumkur and Chitradurga have higher numbers of livestock in absolute terms, however, as far as the LU per lakh population is considered, Yadgir ranks first. The southern districts of Karnataka are dominated by cross-breed cattle, since dairy development has taken place as a major source of economic activity in these districts. The central and northern Karnataka districts are dominated by sheep and goat. The districts of Dharwad, Bijapur, Bagalkot and Belgaum have more numbers of buffaloes.

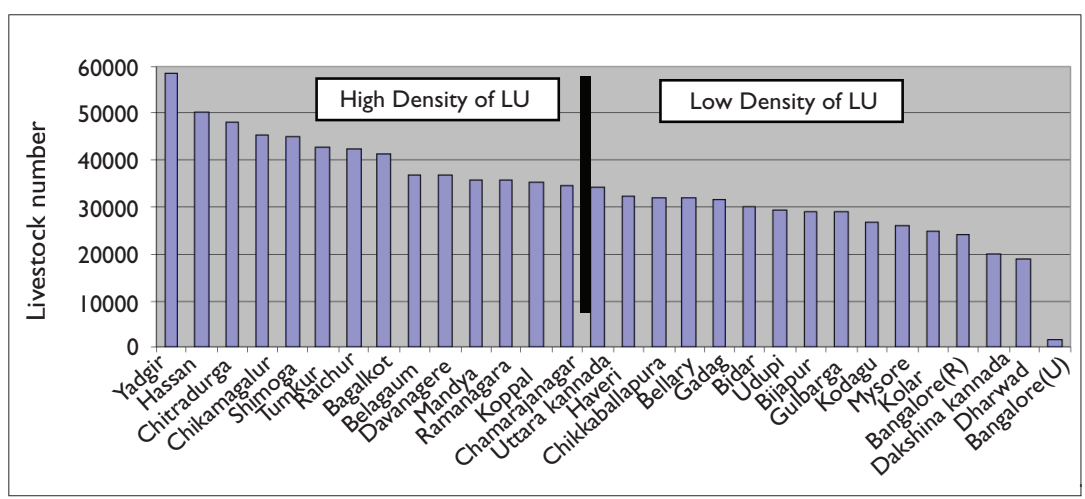

Figure 12. Livestock Units (LU) Per Lakh Population in the Districts of Karnataka

Source: Based on Department of Animal Husbandry and Veterinary Services, Livestock Census 2007. Note: I livestock unit $(\mathrm{LU})=\mathrm{I}$ cow $=$ I buffalo $=5$ sheep $=5$ goats. 


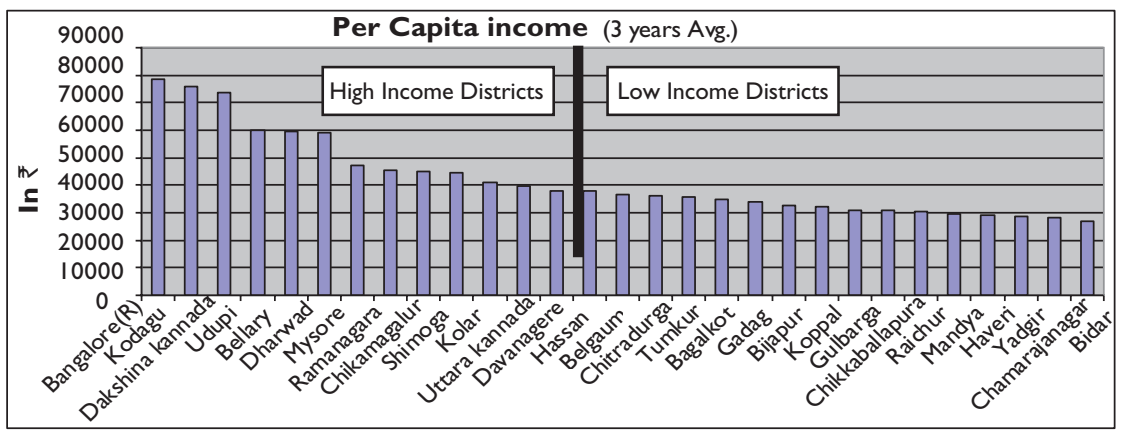

Figure 13. Average Per Capita Income Across the Districts of Karnataka

Source: Based on Directorate of Economics and Statistics Published in Economy Survey Reports of Karnataka, 20I0-20II, 20II-20I2 and 20I2-20I3.

Note: Bangalore Urban is not included here as it is an outlier.

\section{Per Capita Income}

One of the factors affecting the standard of living of people is per capita income. Higher the average per capita income, lesser is the level of economic vulnerability. Bangalore Urban district has the highest per capita income of ₹139,033. Bangalore Rural and Kodagu have an average per capita income of ₹78,587 and ₹75,767, respectively. The Hyderabad-Karnataka region districts like Bidar, Gulbarga, Raichur, Yadgir and Koppal have low per capita income in the states. Bidar district has the least (₹26,905) per capita income in the state. In South Karnataka, the districts of Chamarajanagar and Mandya also have low per capita income. Figure 13 gives the details of per capita income (average of 3 years: 2008-2009, 2009-2010 and 2010-2011) across the districts of Karnataka.

Table 2 presents all the districts of Karnataka, grouped into high and low incidences, indicating higher than the median value and lower than the median value, respectively for all the indicators considered for assessments of livelihood and agricultural vulnerability.

\section{Approach to Vulnerability Assessment}

Vulnerability is often reflected in the state of the economic system as well as the socio-economic features of the population living in that system. This section of the report attempts to build a picture of the socio-economic context of vulnerability by focusing on indicators that measure both the state of development of the people as well as its capacity to progress further. In addition, an attempt has been made to construct a vulnerability index for each district of Karnataka and rank them in terms of their performance on the index. The index attempts to capture the comprehensive scale of vulnerability by considering some of the key indicators (that serve as proxies) for the assessment (Table 3). 


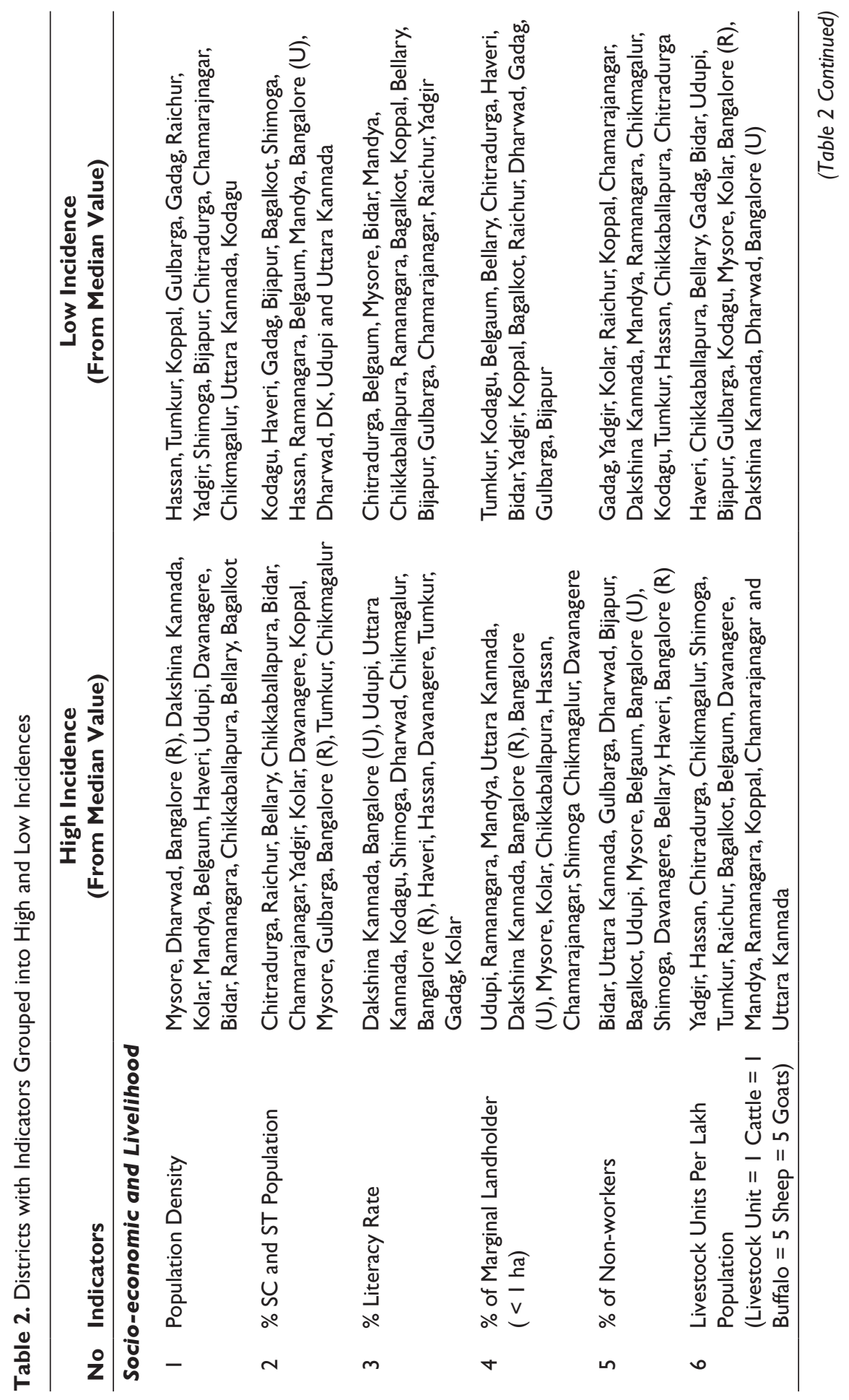




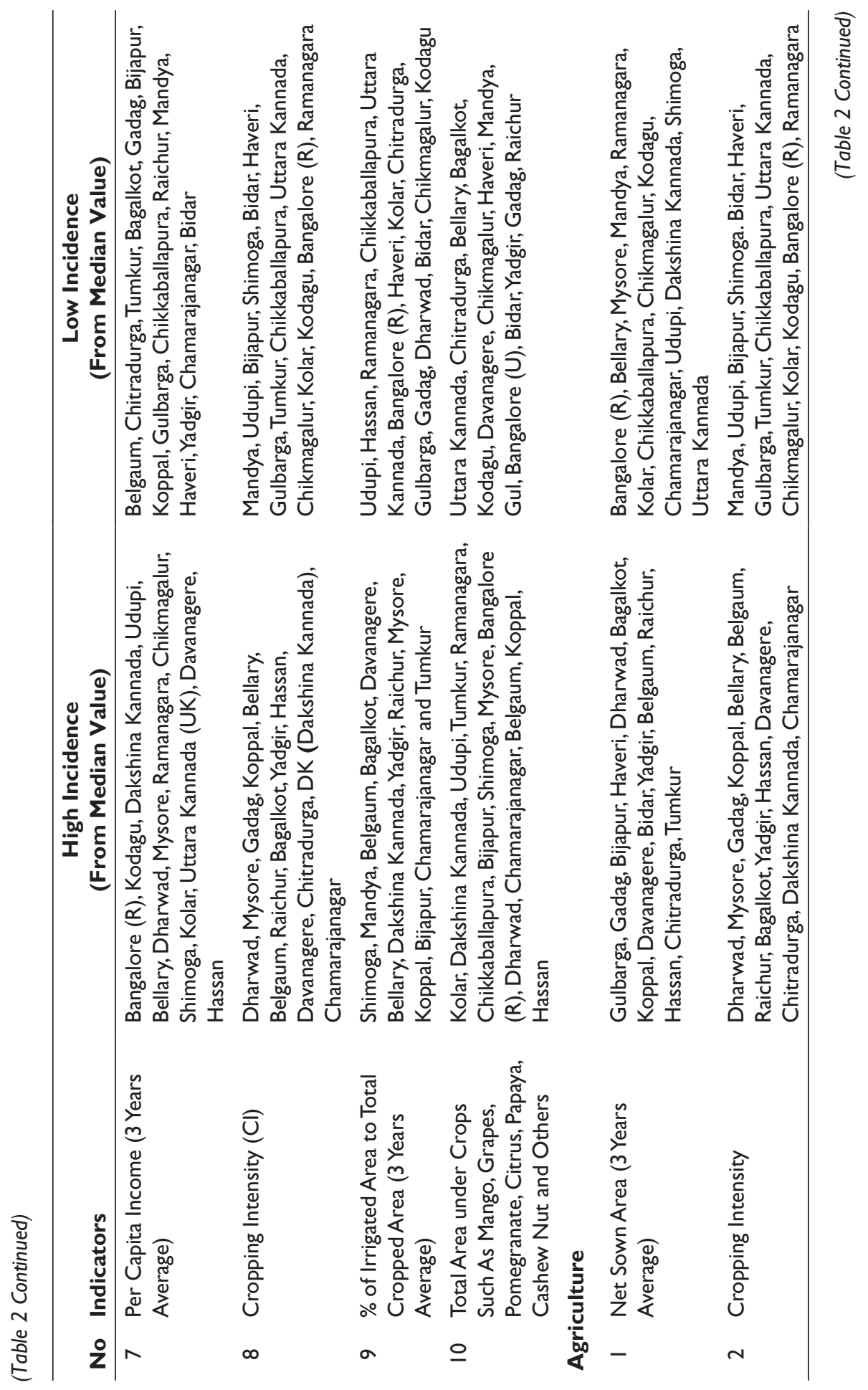




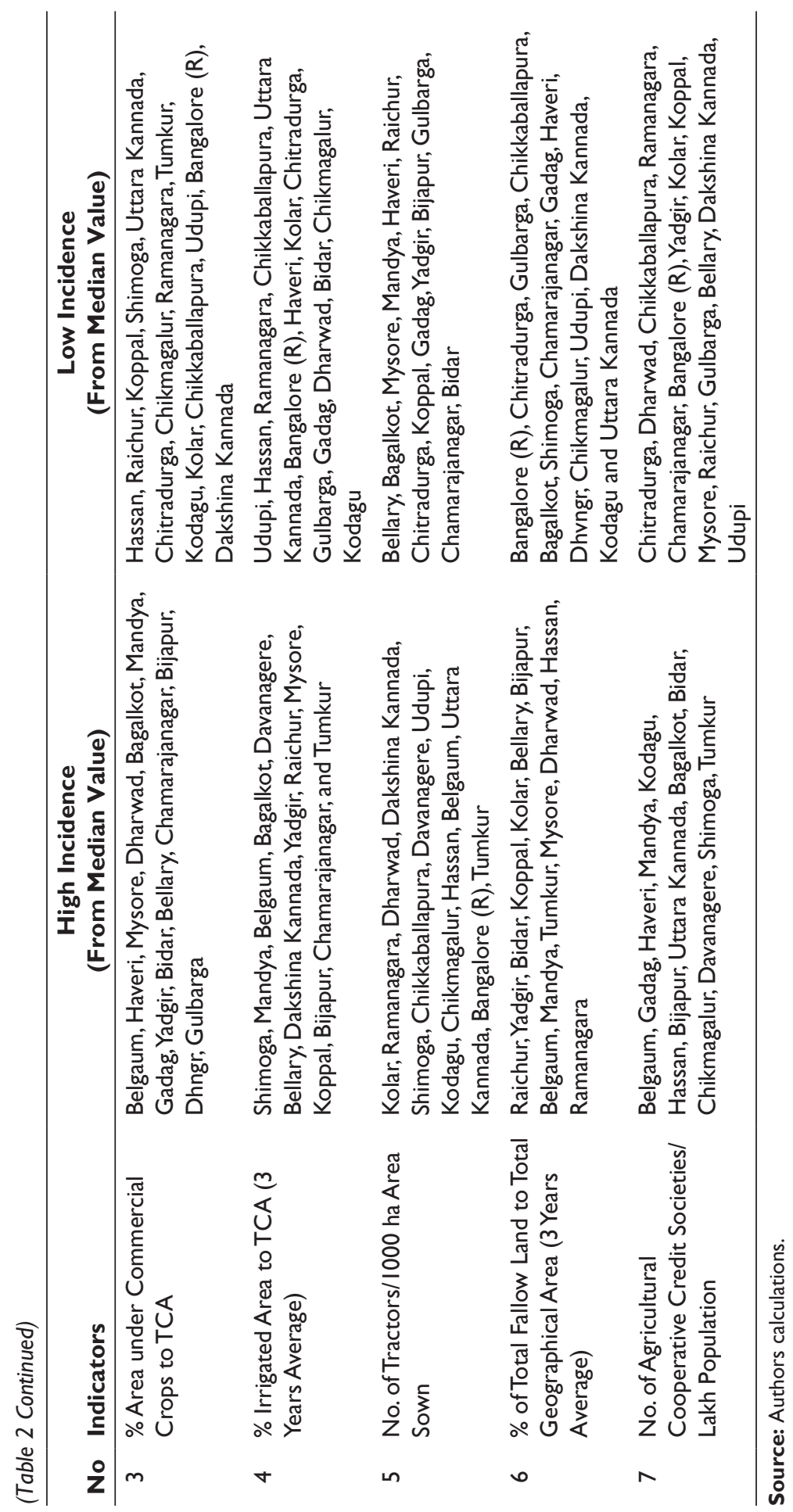




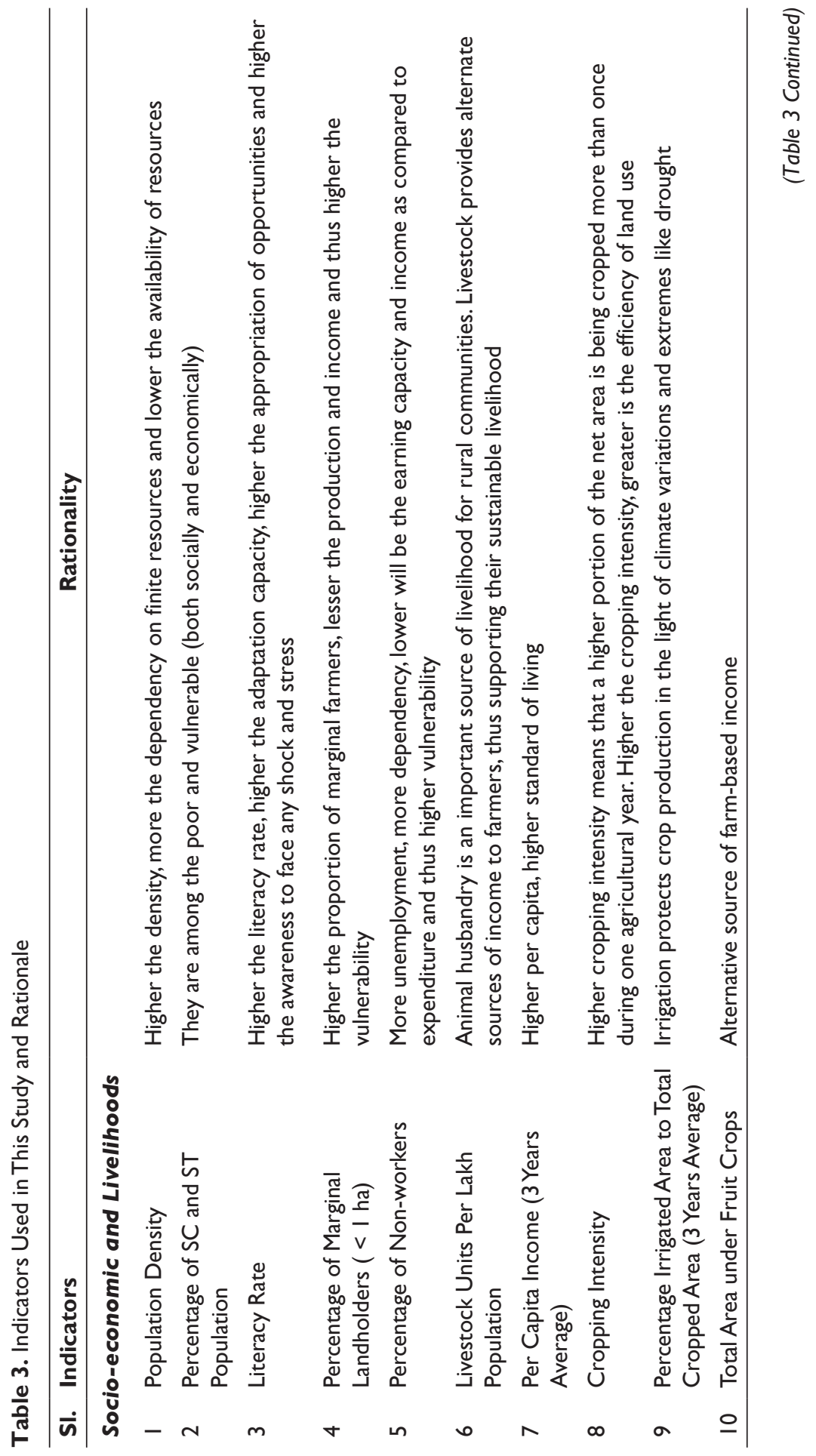




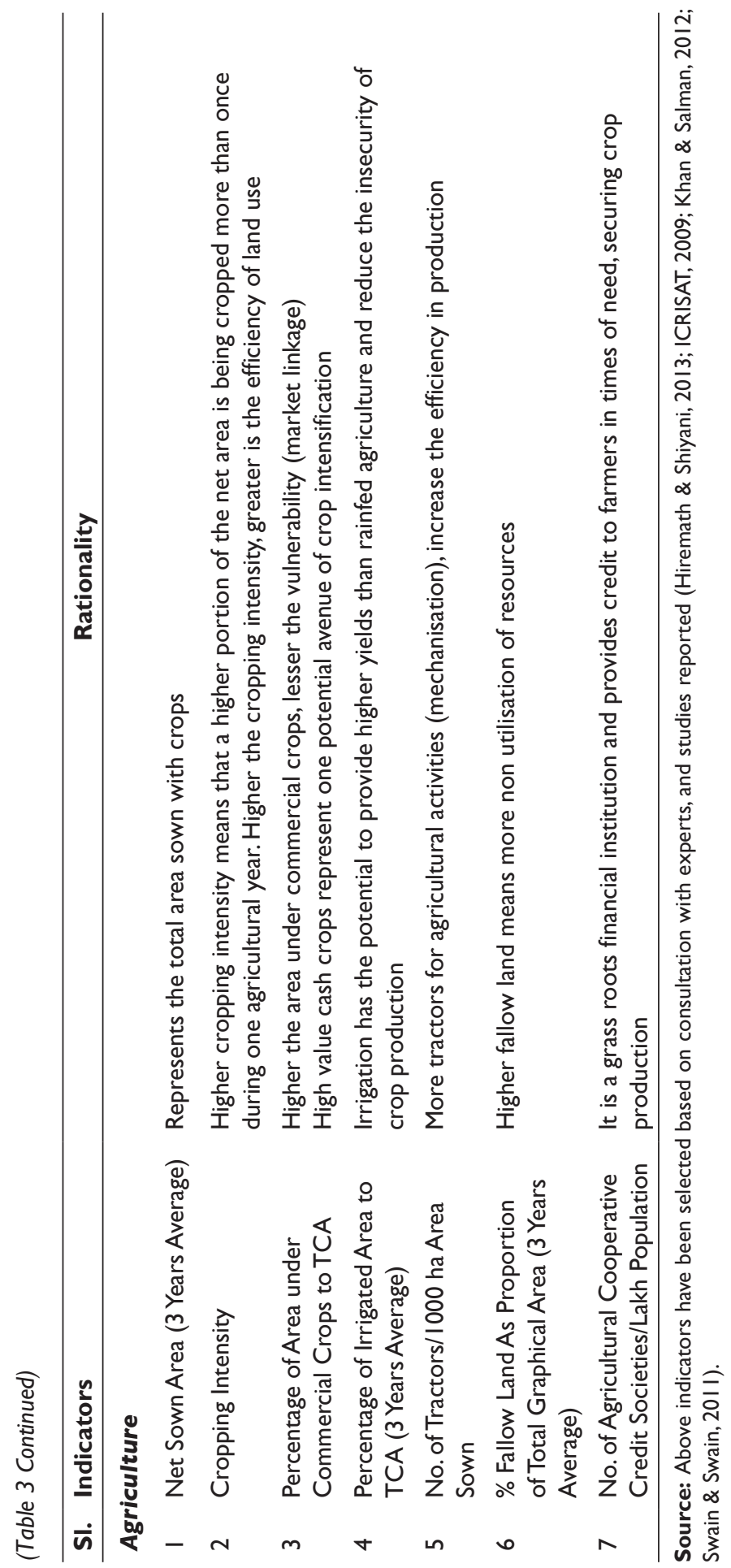


There is consensus among researchers to address vulnerability issues at the regional level (Hiremath \& Shiyani, 2013). Therefore, districts have been taken as a unit for developing vulnerability indices. In the next step, we have selected important indicators for the vulnerability assessment. After the selection of indicators, data pertinent to the selected indicators were compiled (Table 3 ). In the next step, a principal component analysis (PCA) was conducted to identify variability among the selected variables and finally vulnerability indices were developed. Figure 14 presents the details of the method adopted for the assessment of vulnerability across the districts of Karnataka.

\section{Principal Component Analysis (PCA)}

We have chosen the path of getting the weights out of the data using the intrinsic behaviour of the data using PCA. It is well expected that the variables chosen here are internally correlated and, hence, not easily amenable for any functional analysis and these individually follow different probability distributions. Therefore, PCA

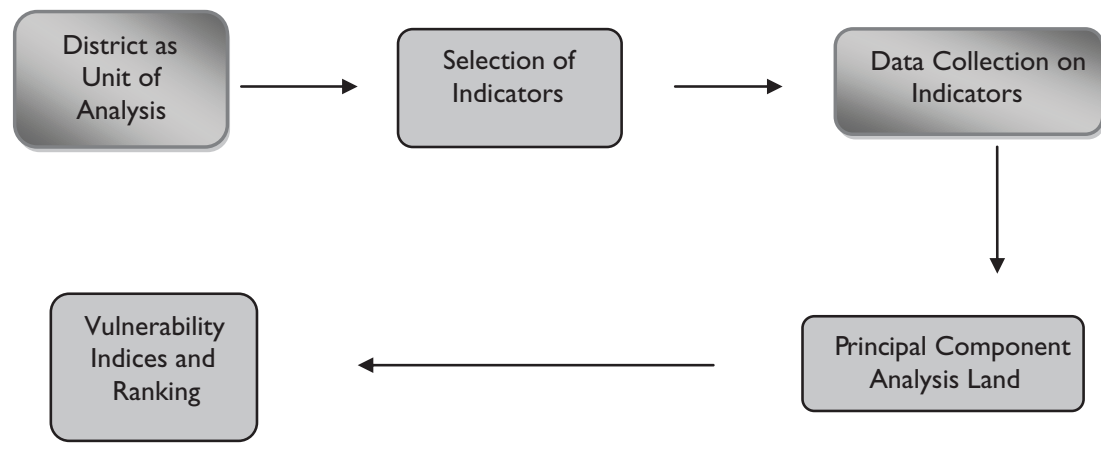

Figure 14. Framework of Assessment of Vulnerability

Source: Author's analysis.

Box I. Concepts

Vulnerability is the degree to which a system is susceptible to or unable to cope with adverse effects of climate change, including climate variability and extremes. Vulnerability is a function of the character, magnitude and rate of climate change to which a system is exposed along with its sensitivity and adaptive capacity.

Exposure is the nature and degree to which a system is exposed to significant climatic variations.

Sensitivity is the degree to which a system can be affected, negatively or positively, by changes in climate. This includes change in mean climate and the frequency and magnitude of extremes. The effect may be direct (for example, a change in crop yield due to a change in temperature) or indirect (such as damage caused by increased frequency of coastal flooding due to sea-level rise).

Adaptive capacity is a system's ability to adjust to climate change (including climate variability and extremes), to moderate potential damage and to take advantage of opportunities or to cope with consequences.

Source: IPCC, Fourth Assessment Report, 2007. 
is the only appropriate tool to get at the weights. There is subjectivity in assigning weights to indicators in vulnerability assessments. In order to overcome this problem, we employed the PCA technique through which we reduced the number of variables and also obtained weights (Eigen values) for the principal components (PCs). In the present study, weights are not, therefore, arbitrarily assigned, but determined endogenously from the data matrix.

A PCA was conducted to identify the variability among the selected variables (indicators) for this study. PCA is a data reduction methodology that identifies smaller number of components that explains most of the variance observed in the larger data set. The goal is to arrive at a minimum number of components that will adequately account for the covariation among the larger number of variables. PCA is a tool that converts a number of potentially correlated variables into a set of uncorrelated numbers that capture the variability in the underlying data and could be used for ordering the regional units. The first PC accounts for a large share of variability in the data and each succeeding component accounts for as much of the remaining variability as possible. PCA approach provides several potential advantages in the aggregation of spatially explicit and potentially incommensurable variables. Excluding the lower order, PCs reduce the dimensionality (number of variables) of the data while minimising the loss of information (Smith, 2002). PCA, thus, helps reduce from a large number of individual indicators to a small number of composite, unit-less indices (PCs) while reducing the trade-off between richness of information and communicability.

PCA helped in the generation of weights, based on the assumption there are common factors that explain the variance in vulnerability. Varimax rotation was performed on the results of the PCA to maximise the variance accounted by the first principal component. Only components with eigenvalues greater than 1 were included in the analysis to effectively organise the process of ordering.

Based on Statistical Package for the Social Sciences (SPSS) output, the findings of the study for the agriculture and socio-economic based classifications on vulnerability indicators revealed three components, each with eigenvalues greater than 1 (Tables 4 and 5). These two PCA results explain 72 per cent and 67 per cent of the total variation in the two data sets. That gives us greater statistical confidence in interpreting the results. The weights of PCs are the corresponding Eigen values (Tables 6 and 7; Figures 15 and 16).

\section{Agricultural Vulnerability Index for the Districts of Karnataka}

In the present study, we considered seven indicators for the development of agricultural vulnerability index (Table 3 ). This was to avoid unnecessary cluttering of variables with marginal improvement in the end results. Based on PCA, agricultural vulnerability index values for all the districts of Karnataka are given in Table 6. Rank 1 indicates maximum vulnerability and the vulnerability decreases with the increasing ranks. Figure 17 depicts the agricultural vulnerability of the districts of Karnataka. Areas in red are the most vulnerable districts and those in green are the least vulnerable districts of Karnataka. Table 8 gives the details of significance of variables that explain variation in each component. 

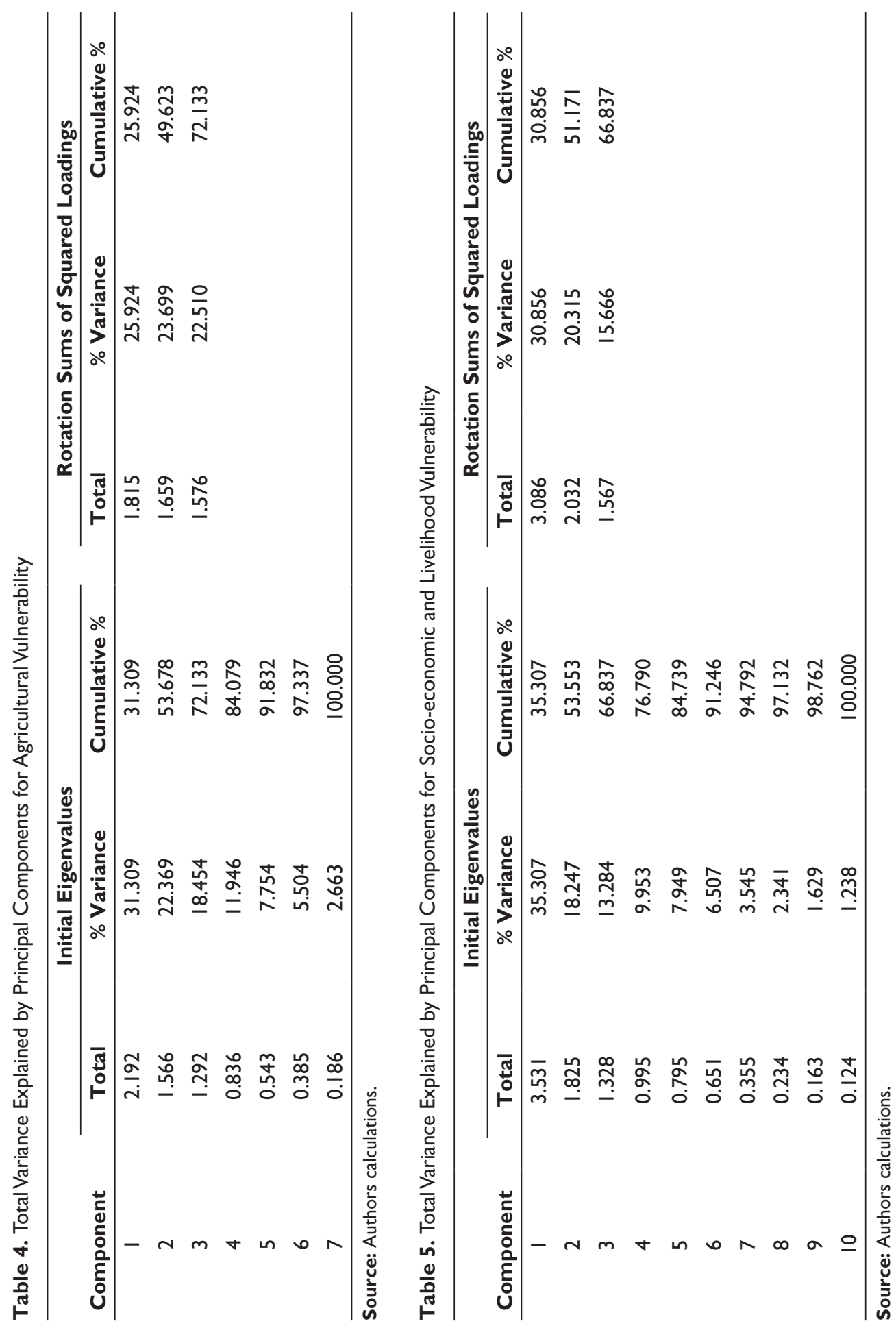


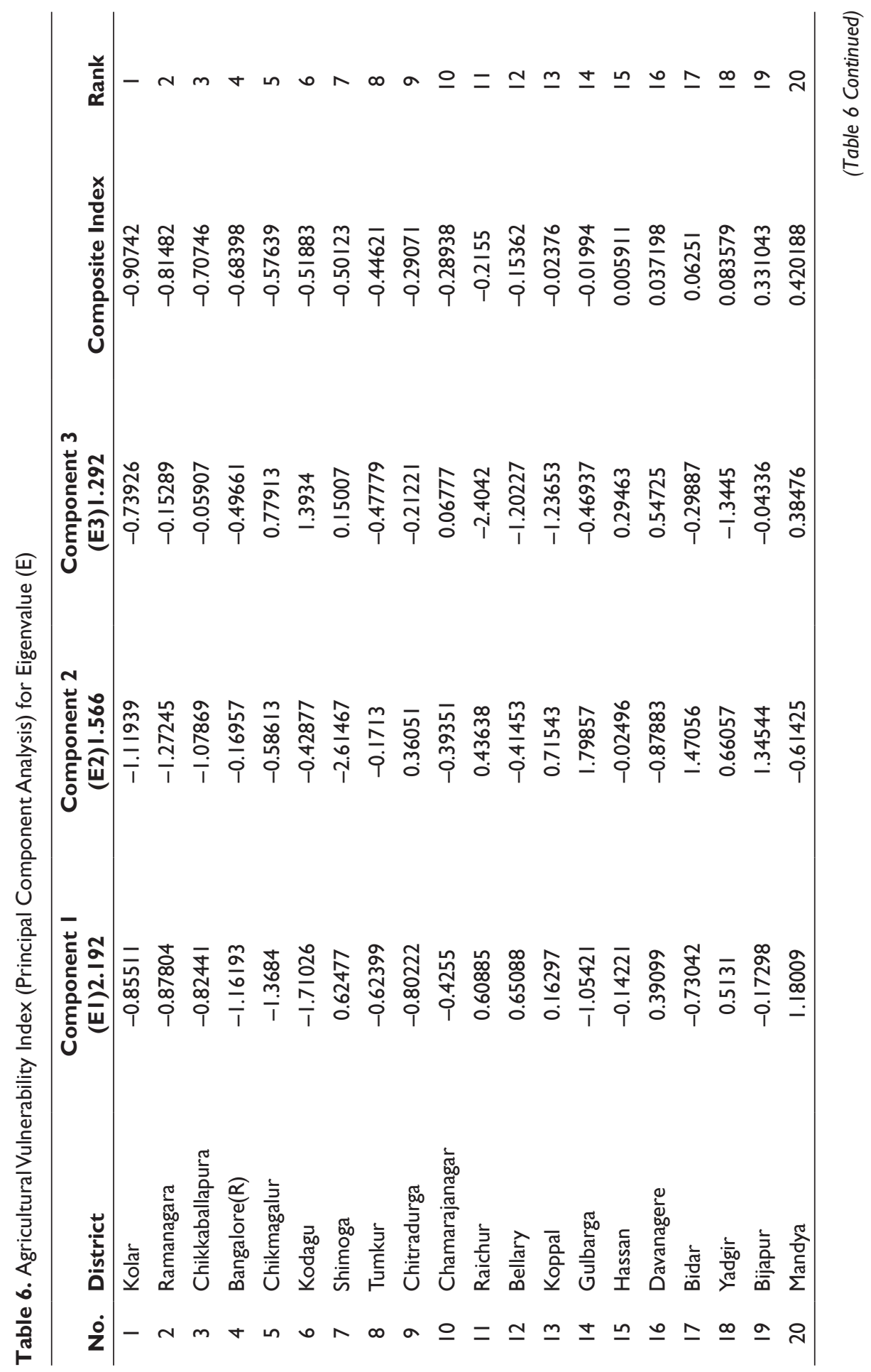




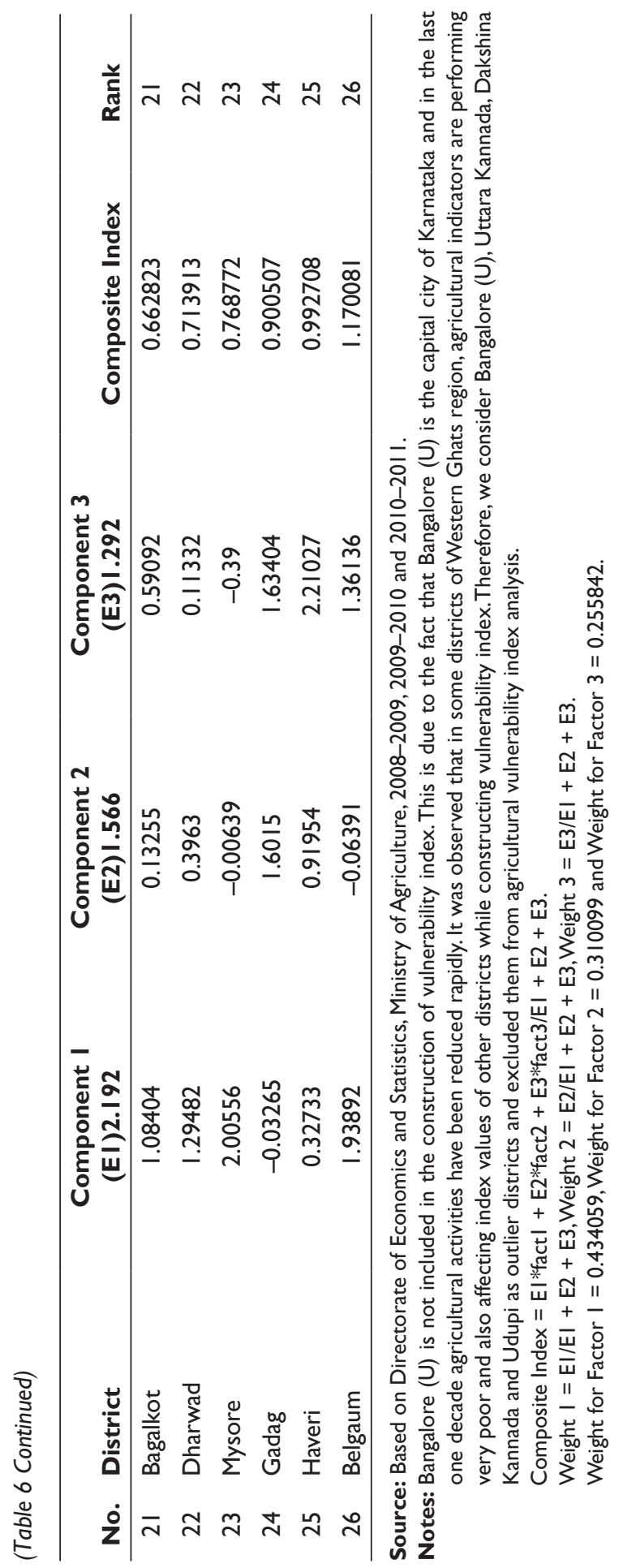




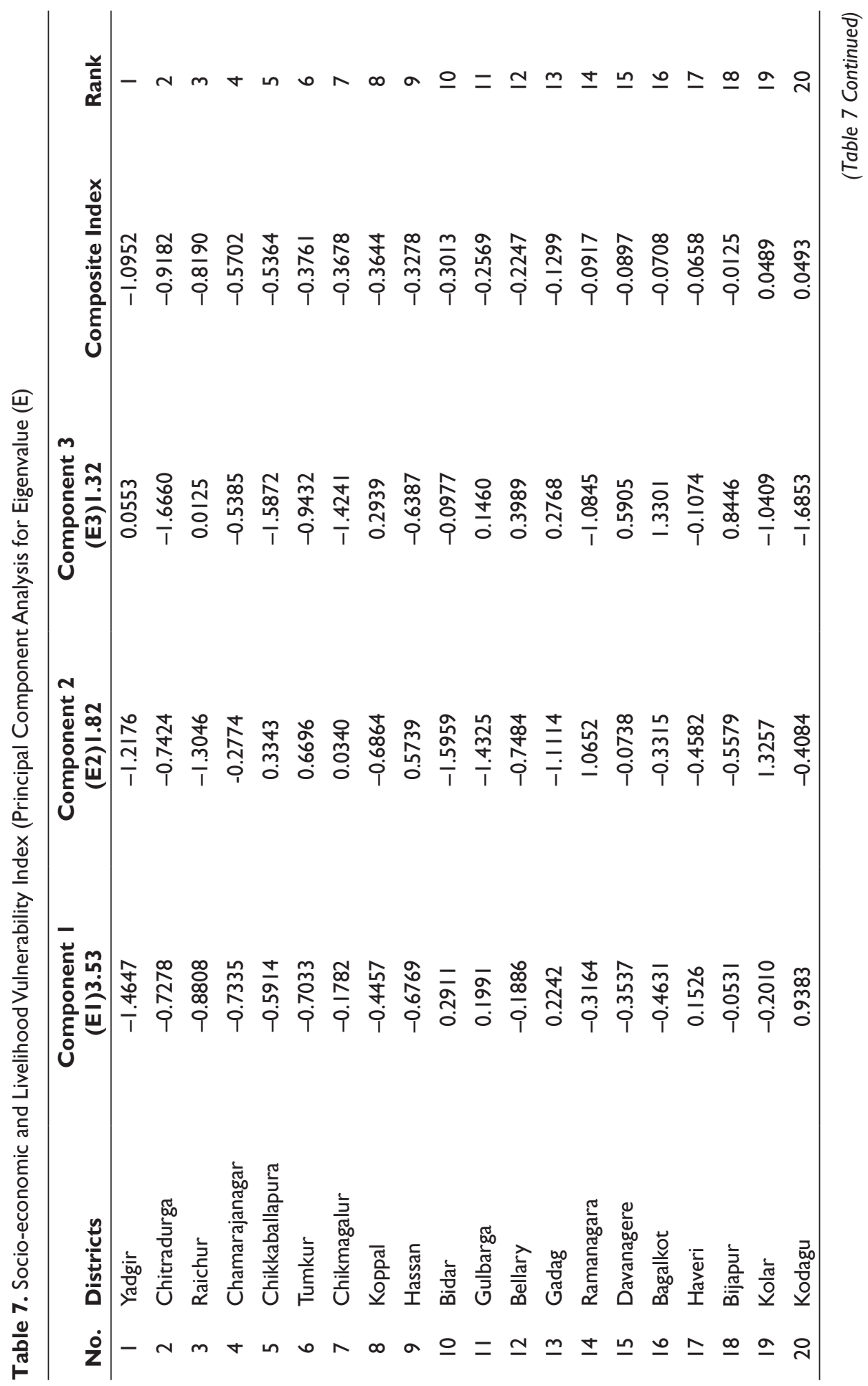




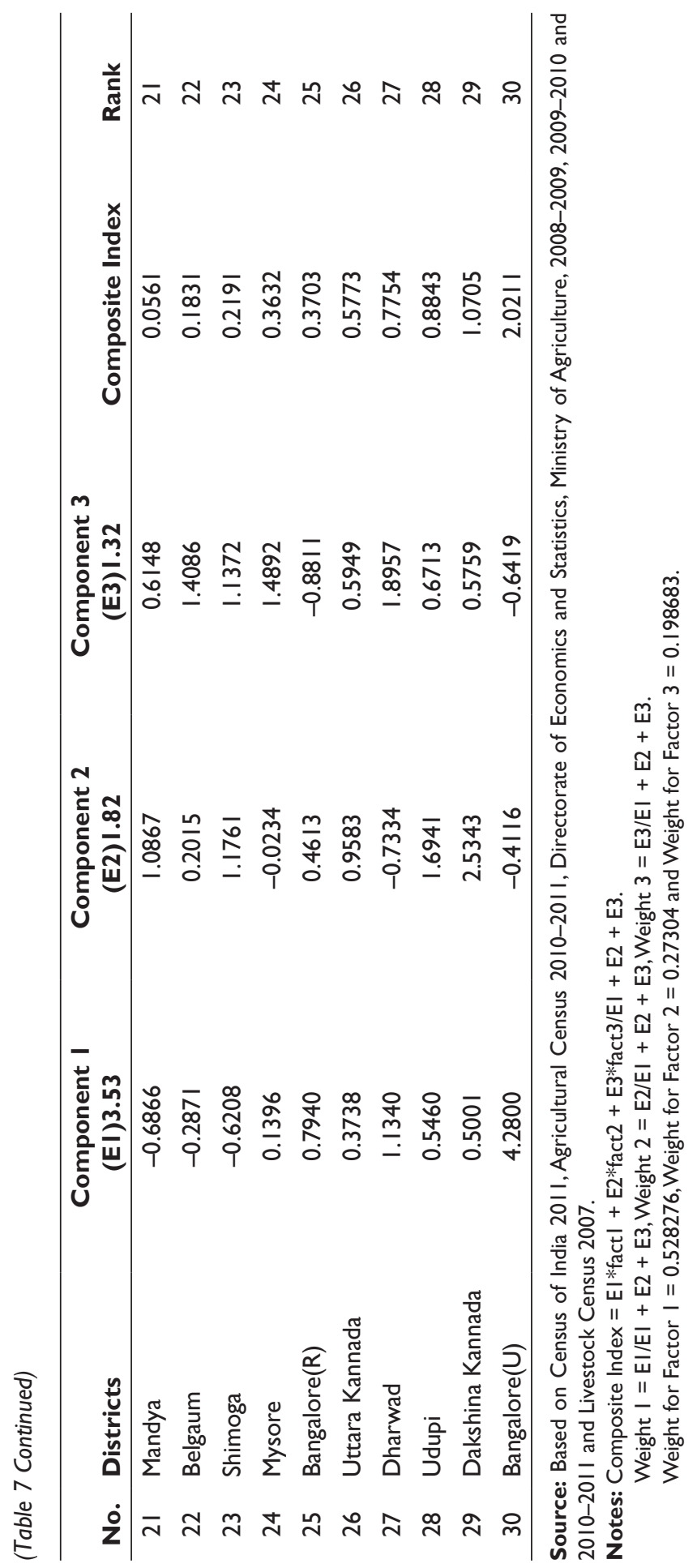


Table 8. Rotated Component Matrix

\begin{tabular}{lccc}
\hline & \multicolumn{3}{c}{ Component } \\
\cline { 2 - 4 } Agricultural Indicators & $\mathbf{I}$ & $\mathbf{2}$ & $\mathbf{3}$ \\
\hline $\begin{array}{l}\text { \% of Net Sown Area to Total Geographical Area (TGA) } \\
\text { (3 Years Average) }\end{array}$ & 0.190 & 0.836 & 0.085 \\
Cropping Intensity & & & \\
\% of Gross Irrigated Area to Total Cropped Area (TCA) & 0.754 & 0.269 & 0.089 \\
(3 Years Average) & & 0.369 & 0.220 \\
\% of Fallow Land to TGA (3 Years Average) & 0.286 & 0.237 & 0.779 \\
\% of Area under Commercial Crops to TCA & 0.793 & 0.284 & 0.415 \\
No. of Tractors/I000 ha Area Sown & 0.007 & 0.772 & 0.103 \\
Agricultural Cooperative Societies/Lakh Population & 0.172 & 0.140 & 0.850 \\
\hline
\end{tabular}

Source: Authors calculations.

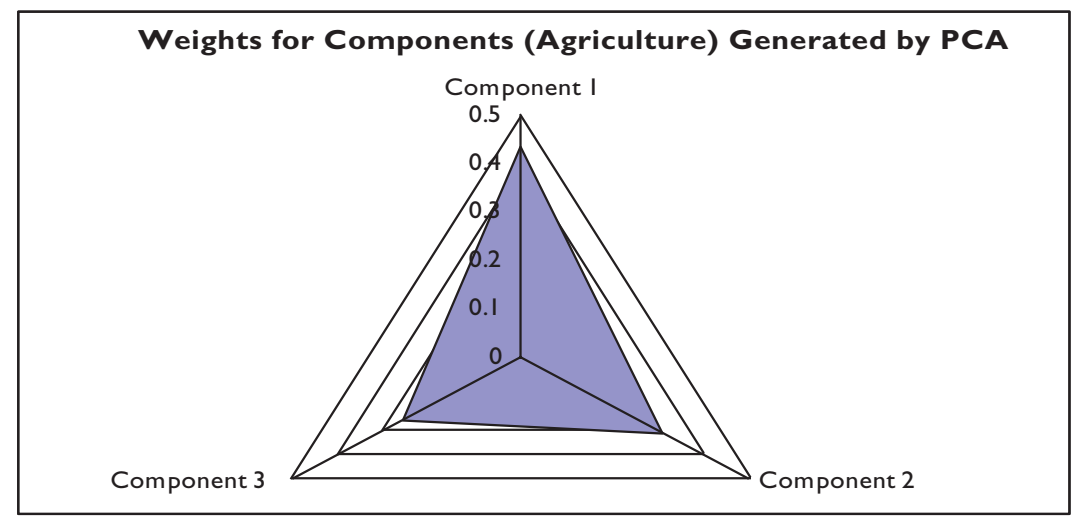

Figure 15. Weights for Agricultural Component Indicators Generated by PCA Source: Author's analysis.

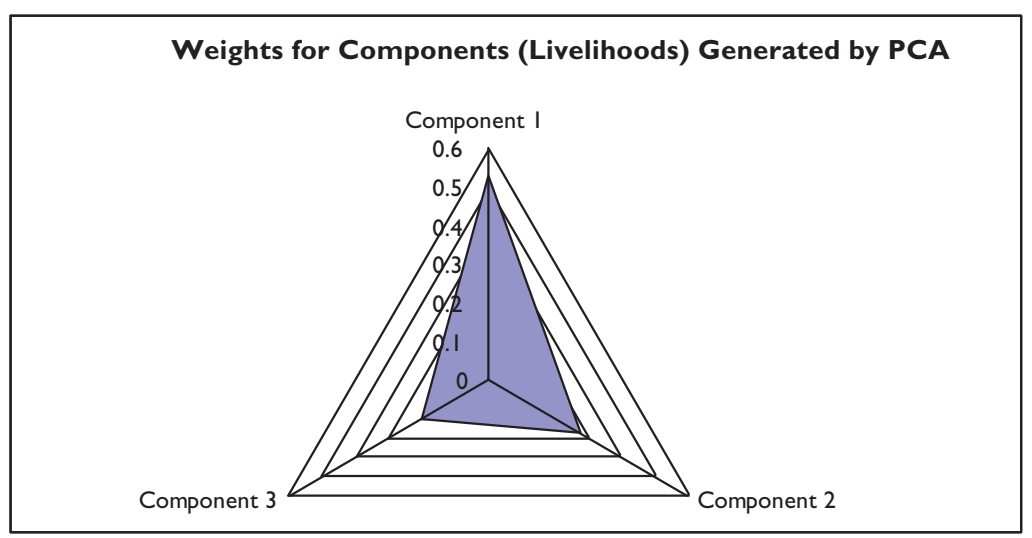

Figure 16. Weights for Socio-economic Component Indicators Generated by PCA

Source: Author's analysis. 
- The rotated factor analysis generated 3 components that account for approximately 72 per cent of the total cumulative variance in agricultural vulnerability.

- In component 1, 26 per cent of variation is explained by 3 variables, namely, percentage of gross area irrigated, CI and percentage of commercial crops to TCA.

- In component 2, 24 per cent of variation is explained by 2 variables, namely, percentage of NSA to total geographical area and number of tractors/1000 hectares area sown.

- In component 3,22 per cent of variation is explained by 2 variables, that is, percentage of fallow land to total geographical area and ACS/lakh population.

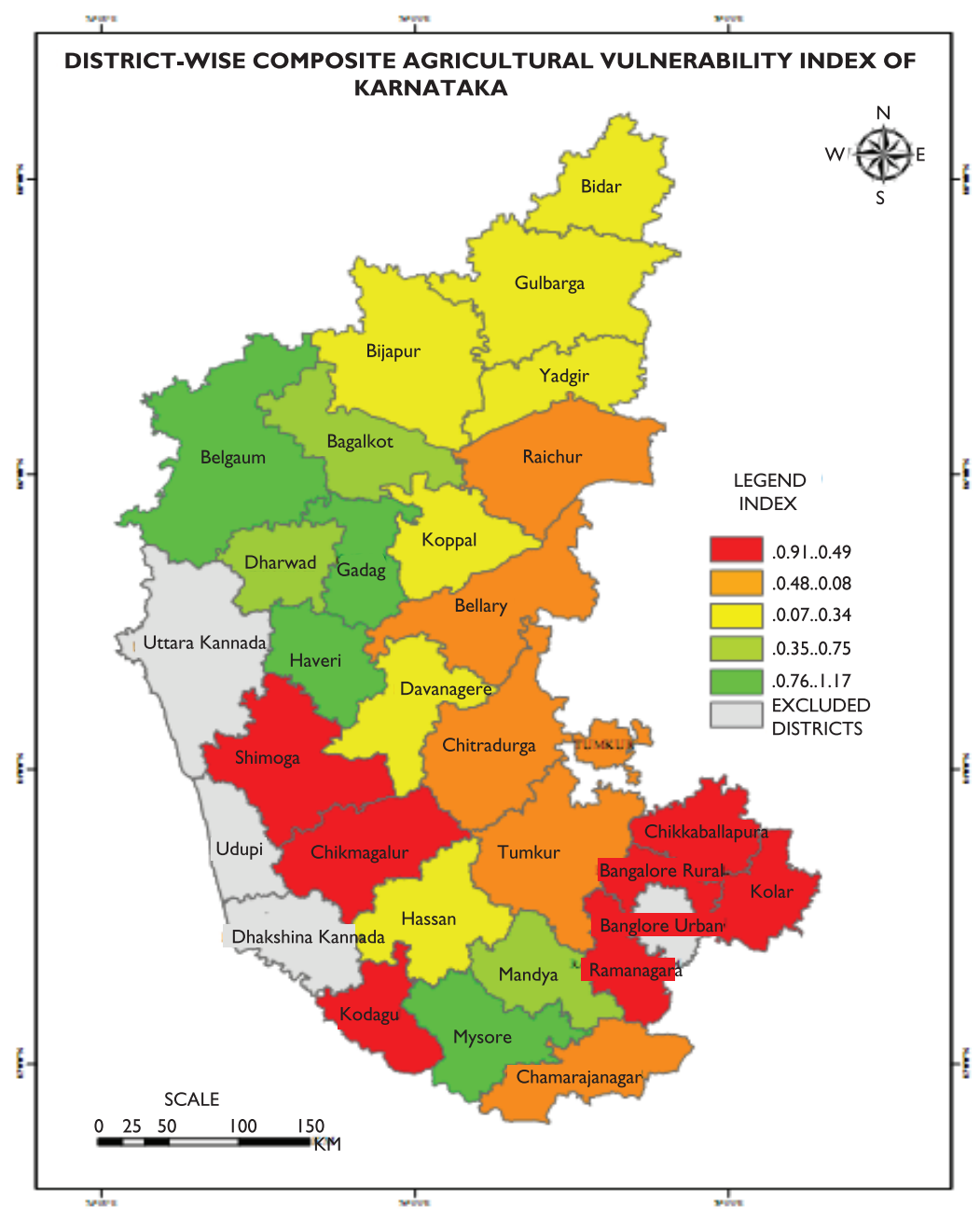

Figure 17. Agricultural Vulnerability Index

Source: Provided by the author.

Notes: Areas in red are the most agriculturally vulnerable districts and those in green are the least agriculturally vulnerable districts of Karnataka. Bangalore $(U)$ is not included. 
An important improvement here is the avoidance of arbitrary or normative weights and not getting into the trap of a bold assumption of similar probability distributions to the components even though these components come from varied statistical domains. We have also avoided cluttering of variables by eliminating some of these prior to undertaking the analysis.

\section{Socio-economic Vulnerability Index for the Districts of Karnataka}

For the development of the socio-economic vulnerability index, 10 important indicators, described in Table 3, were considered. As agriculture is a dominant livelihood activity, a few agricultural indicators have also been included in the development of this index.

In Table 7, Rank 1 indicates maximum vulnerable district and the vulnerability decreases with the increasing ranks. PCA shows that Yadgir, Chitradurga, Raichur, Chamarajanagar and Chikkaballapura are the top five socio-economically vulnerable districts. Bangalore (U), Dakshina Kannada, Udupi, Dharwad and Uttara Kannada are the least socio-economically vulnerable districts of Karnataka. Figure 18 depicts the socio-economically vulnerable districts of Karnataka, with red and green coloured areas representing the most and the least vulnerable districts, respectively. Table 9 gives the details of the significance of variables that explain variation in each component.

Table 9. Rotated Component Matrix (a)

\begin{tabular}{lccc}
\hline & \multicolumn{3}{c}{ Component } \\
\cline { 2 - 4 } Socio-economic Indicator & $\mathbf{I}$ & $\mathbf{2}$ & $\mathbf{3}$ \\
\hline Density of Population & 0.825 & 0.040 & 0.076 \\
\% SC \& ST Population & 0.467 & 0.529 & 0.404 \\
Total Literacy Rate (\%) & 0.628 & 0.558 & 0.001 \\
\% of Marginal Landholders & 0.172 & 0.802 & 0.229 \\
\% of Non-workers & 0.329 & 0.224 & 0.739 \\
Livestock Units Per Lakh Population & 0.850 & 0.105 & 0.107 \\
(3 Years Average) Per Capita Income & 0.875 & 0.202 & 0.112 \\
Cropping Intensity & 0.142 & 0.302 & 0.668 \\
\% Gross Irrigated Area to Total Cropped & 0.382 & 0.272 & 0.563 \\
Area (3 Years Average) & & & \\
Total Fruit Crops Area & 0.034 & 0.728 & 0.110 \\
\hline
\end{tabular}

Source: Authors calculations. 


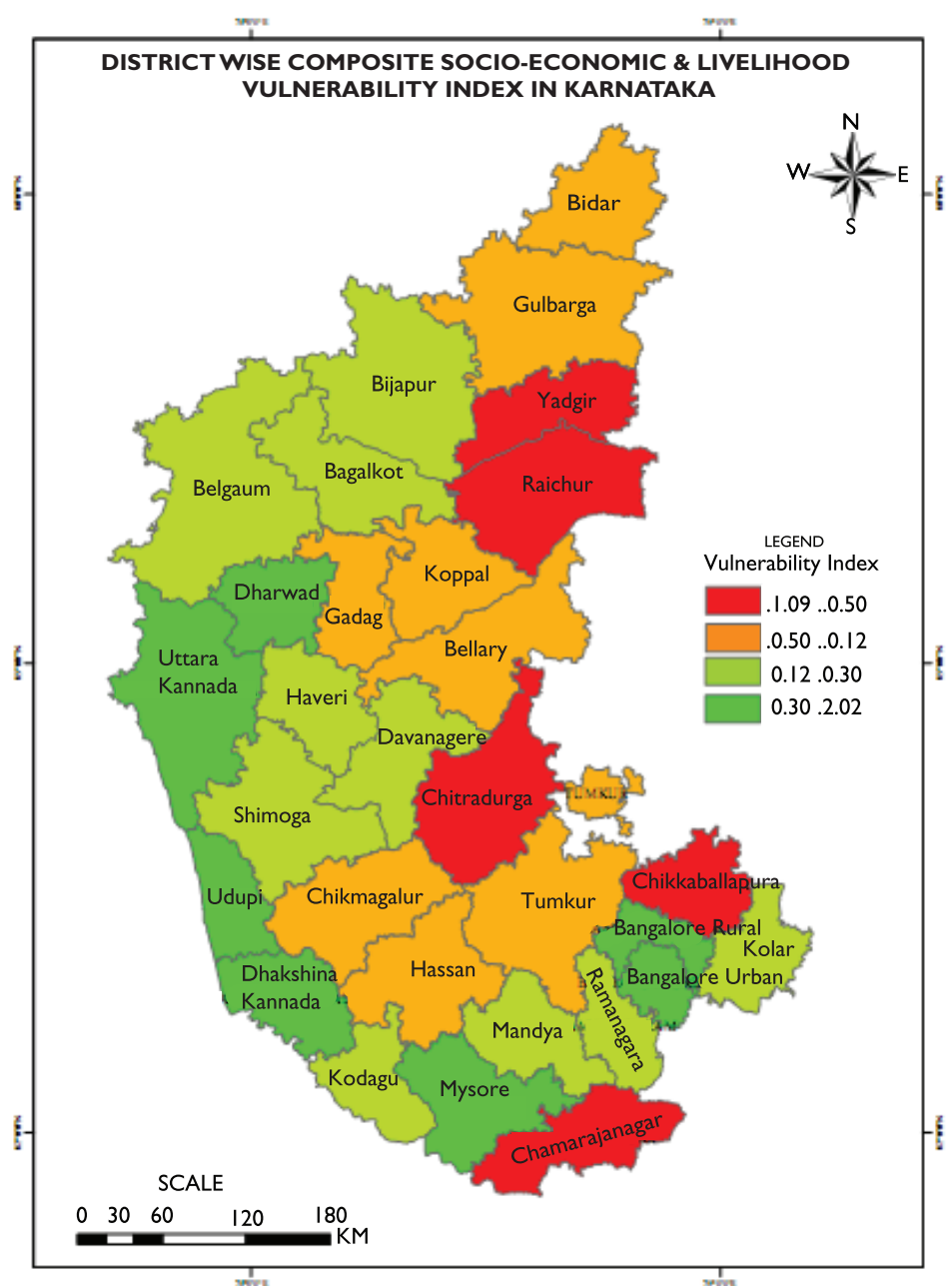

Figure 18. Socio-economic Vulnerability Index

Source: Provided by the author.

Note: Areas in red are the most socio-economically vulnerable districts and those in green are the least socio-economically vulnerable districts of Karnataka.

- The rotated factor analysis generated 3 components that account for approximately 67 per cent of the total cumulative variance in socioeconomic and livelihood vulnerability.

- Factor 1 that accounts for the largest variance (about 31 per cent) includes population density, percentage of LR, livestock unit/lakh population and per capita income.

- In component 2, 20 per cent variation is explained by 3 variables, namely, percentage of SC and ST population, percentage of marginal landholders and total area under fruit crops.

- In factor 3, 16 per cent of variation is explained by 3 variables, namely, percentage of non-workers, CI and percentage of irrigated area. 


\section{Discussion and Drivers of Vulnerability}

Karnataka is one of the fastest-growing economies in India. Agriculture in Karnataka is predominantly rainfed. In the present study, two vulnerability indices were developed at the district level: agricultural vulnerability index and socioeconomic vulnerability index, considering all the 30 districts of Karnataka for the analysis.

In order to derive these indices, a PCA was run on a data set of 10 carefully selected indicator variables to represent socio-economic vulnerability and 7 indicators for agricultural vulnerability across the districts of Karnataka. The PCA generated three components for each index that broadly represented the underlying themes of agriculture and socio-economic vulnerability present in the larger data set. The findings suggest:

- Agricultural vulnerability

- Kolar, Ramanagara, Chikkaballapura and Bangalore (R) are the most vulnerable districts of Karnataka.

- Belgaum, Haveri and Gadag are the least vulnerable districts.

- Socio-economic and livelihood vulnerability

- Yadgir, Chitradurga, Raichur, Chamarajanagar and Chikkaballapura districts are the most vulnerable among all the districts of Karnataka

- Bangalore (U), Dakshina Kannada, Udupi, Dharwad and Uttara Kannada are the least vulnerable districts of Karnataka.

The result of agricultural vulnerability index suggests indicators such as CI, gross area irrigated and commercial crop area are the major drivers in determining the vulnerability of districts. The livelihood vulnerability index analysis suggests Yadgir, Chitradurga, Raichur, Chamarajanagar and Chikkaballapura are the most vulnerable districts in Karnataka. The socio-economic and livelihood index depicts indicators like per capita income, population density, percentage of LR and LU/lakh population, which are the major drivers and contribute to the overall livelihood vulnerability of districts.

\section{Note}

1. This article, based on a larger study was supported by the Global Green Growth Institute and carried out by the Center for Ecological Economics and Natural Resources of Institute for Social and Economic Change, Bangalore, India.

\section{References}

Adger, W., Neil., Brooks, Nick, Bentham, Graham, Agnew, Maureen, \& Eriksen, Siri. (2004). New indicators of vulnerability and adaptive capacity (Technical Report 7). Norwich, UK: Tyndall Centre for Climate Change Research. 
Allen, K. (2003). Vulnerability reduction and the community-based approach. In Pelling, M. (Ed.), Natural disasters and development in a globalizing world (pp. 170-184). London, UK: Routledge.

Fussel, H.M. (2007). Vulnerability: A generally applicable conceptual framework for climate change research. Global Environmental Change, 17(2), 155-167.

Government of India. (2012a). Census of India-2011. New Delhi: Government of India.

- (2012b). Agricultural statistics, Ministry of Agriculture, New Delhi.

Government of Karnataka. (2005). Human development report, Karnataka. Bangalore: Government of Karnataka.

Government of Karnataka. (2012). Statistical Abstract for 2010-11. Department of Economics and Statistics, Planning Department, Bangalore.

Hiremath, D., \& Shiyani, R.L. (2013). Analysis of vulnerability indices in various agroclimatic zones of Gujarat. Indian Journal of Agricultural Economies, 68(1), 122.

ICRISAT. (2009). Quantitative assessment of vulnerability to climate change. Retrieved 10 August 2013, from http://www.icrisat.org/what-we-do/impi/training-cc/october-2-3 2009/vulnerability-analysis-manual.pdf

IISc. (2013). Environmental benefits and vulnerability reduction through Mahatma Gandhi national rural employment guarantee scheme (Synthesis Report 2013). Bangalore: Indian Institute of Science.

IPCC. (1996). Climate change 1995 second assessment report of the intergovernmental panel on climate change. Geneva, Switzerland.

- (2001). Climate change 2001: The scientific basis-Contribution of working group I to the third assessment report of the intergovernmental panel on climate change. Cambridge, UK: Cambridge University Press.

- (2007). IPCC fourth assessment report: Climate change 2007 (AR4). Cambridge, UK: Cambridge University Press.

Karade, J. (2008). Development of Scheduled Castes and Scheduled Tribes in India. UK: Cambridge School of Publishing.

Khan, F.A., \& Salman, A. (2012). A simple human vulnerability index to climate change hazards for Pakistan. International Journal of Disaster Risk Science, 3(3), 163-176.

Nicholls, R.J., Hoozemans, F.M.J., \& Marchand, M. (1999). Increasing flood risk and wetland losses due to global sea-level rise: Regional and global analyses. Global Environmental Change, 9, S69-S87.

Senbeta, A.F. (2009). Climate change impact on livelihood, vulnerability and coping mechanisms: A case study of West Arid Zone, Ethiopia (MSc thesis, Lund University Masters Program in Environmental Studies and Sustainability Science [LUMES], Lund, Sweden).

Smith, L.I. (2002). A tutorial on principal component analysis. Vol. 2012. Retrieved 22 November 2016, from http://faculty.iiit.ac.in/ mkrishna/PrincipalComponents.pdf. (Anton, H. [1987]. Elementary linear algebra 5e. New York, NY: John Wiley \& Sons Inc. ISBN 0-471-85223-6.)

Stern, N., Peters, S., Bakhshi, V., Bowen, A., Cameron, C., Catovsky, S., Dietz, S. (2006). Stern review: The economics of climate change. Oxford, UK: OUP.

Swain, M., \& Swain, M. (2011). Vulnerability to agricultural drought in Western Orissa: A case study of representative blocks. Agricultural Economics Research Review, 24, $47-56$.

Watson, R.T., Zinyoera, M.C., \& Moss, R.H. (1996). The regional impact of climate change: An assessment of vulnerability (A Special Report of IPCC Working Group II). Cambridge, UK: Cambridge University Press. 